\title{
Synthesis and affinities of C3-symmetric thioglycoside-containing trimannosides
}

\author{
Jingjing Bi ${ }^{\text {a, b }}$, Chuanfang Zhao a, b, Wei Cui ${ }^{\text {b }}$, Chaoli Zhang ${ }^{\text {a, b }}$, Qiuli Shan ${ }^{\mathrm{a}, \mathrm{b}}$, \\ Yuguo $\mathrm{Du}^{\mathrm{a}, \mathrm{b}, \mathrm{c}, *}$ \\ a State Key Laboratory of Environmental Chemistry and Eco-toxicology, Research Center for Eco-Environmental Sciences, Chinese Academy of Sciences, \\ Beijing 100085, China \\ b School of Chemistry and Chemical Engineering, University of Chinese Academy of Sciences, Beijing 100049, China \\ ${ }^{\mathrm{c}}$ National Engineering Research Center for Carbohydrate Synthesis, Jiangxi Normal University, Nanchang 330022, Jiangxi, China
}

\section{A R T I C L E I N F O}

\section{Article history:}

Received 23 March 2015

Received in revised form

6 May 2015

Accepted 7 May 2015

Available online 16 May 2015

\section{Keywords:}

Thiooligosaccharides

Glucocluster

Mutivalent effect

Con A

Hemagglutination

\begin{abstract}
A B S T R A C T
Thioglycoside-containing trimannose analogs were designed and prepared to mimic the natural $\mathrm{N}$ glycan core trisaccharide $\alpha$-D-Man- $(1 \rightarrow 3)-[\alpha$-D-Man- $(1 \rightarrow 6)]$-D-Man. $(1 \rightarrow 6)-S$-Linked trimannoside 1 and its trivalent cluster $\mathbf{2}$ were synthesized in 11 and 15 steps, respectively, taking advantages of the armed mannopyranosyl trichloroacetimidate as glycosyl donor. Hemagglutination inhibition of the two new thiomannotriose analogs was preliminarily examined. Comparing to the parent trimannoside $\alpha$-D-Man$(1 \rightarrow 3)$-[ $\alpha$-D-Man- $(1 \rightarrow 6)]$-D-Man-OMe, the cluster mannotrioside 2 presented a comparable binding affinity to Con A, while the monomer 6-S-trimannoside $\mathbf{1}$ exhibited a slightly lower inhibition ability.
\end{abstract}

() 2015 Elsevier Ltd. All rights reserved.

\section{Introduction}

Carbohydrate-protein interaction is one of the most important pathways for biological information exchange between cells and cell substrates. On cell surface, oligosaccharides contribute significant binding sites for inflammation, viral infections, and cancer metastasis. ${ }^{1-4}$ As a counterpart protein in this interaction, lectins mediate attachment and binding of bacteria and viruses accordingly, and also mediate the first-line defense against invading microorganisms with the mannan-binding lectin in the innate immune system. ${ }^{5,6}$ It is hypothesized that some hepatitis $C$ viral glycoproteins attach to C-type lectins on the host liver cell surface for infection. Lectin activities may be inhibited through binding specific sugar structures and in turn prevent their further attachment to the carbohydrates within the host cell membrane. ${ }^{7}$ Con A, one of the most frequently studied member of the legume lectin family, are believed to bind specifically to certain structures found in various sugars, glycoproteins, and glycolipids, mainly internal and non-reducing terminal $\alpha$-D-mannosyl residues. Due to its

\footnotetext{
* Corresponding author.

E-mail address: duyuguo@rcees.ac.cn (Y. Du).
}

commercial availability and a wide variety of sugar specificity, Con A has been used widely as a model system to understand the molecular basis of how proteins recognize carbohydrates. ${ }^{5-9}$

The low affinity in carbohydrate-protein interaction limited their potential medicinal application. But, some proteins, such as lectin, contains typically two or more carbohydrate-combining sites, i.e., they are di- or polyvalent. Multivalent interactions were thus proposed to achieve effective adhesion through many individual binding events. ${ }^{10,11}$ There has been considerable reports in designing multivalent or clustered carbohydrate analogs for highaffinity binding. ${ }^{12-14}$ For instance, Bundle and co-workers reported that the in vitro inhibitory activity of decameric STARFISH for Shiga-like toxins was $10^{6}$-fold higher than that of the monomeric species. ${ }^{15}$ Recently, multivalent mannoside and trimannoside analogs have been synthesized and evaluated in order to obtain increased affinity for lectins. ${ }^{16,17}$ The isothermal titration microcalorimetry data indicated that tri- and tetravalent trimannoside analogs showed 11- and 35-fold higher $K_{a}$ values for Con $A$, respectively, in comparison with the parent trimannoside. ${ }^{16} \mathrm{We}$ have also reported a synthesis of $\mathrm{C}_{3}$-symmetric $(1 \rightarrow 6)-\mathrm{N}$-acetyl- $\beta$ D-glucosamine octadecasaccharide with enhanced antitumor activity against $\mathrm{H}_{22}$ in the preliminary mice tests. ${ }^{18}$ 
To improve the chemical and biological stability against enzymatic cleavage and acid/base hydrolysis, the anomeric oxygen of $\mathrm{O}-$ glycosides were replaced by sulfur or carbon atom generating unnatural S-linked or C-linked glycosides, which kept the similar conformation to their natural O-glycosides and applied as potential probes for enzyme-inhibition studies. ${ }^{19-23}$ Jiménez-Barbero and co-workers reported that C-glycosyl analog of methyl 3,6-di-O- $(\alpha-$ D-mannopyranosyl)- $\alpha$-D- mannopyranoside [abbreviated as Man(3,6)Man-OMe] displayed an enhanced flexibility and could be recognized by Con $\mathrm{A}$ in the similar binding way as the natural trimannose. ${ }^{24}$ Based on these supporting results, we here report our design and synthesis of two new mannotriose analogs, 6-thiolinked mannotriose $\mathbf{1}$ and its trivalent cluster $\mathbf{2}$ (Fig. 1). The binding affinities of these thiooligosaccharides toward Con A were evaluated by the hemagglutination assay, and the trivalent cluster 2 showed a comparable binding ability to Con A versus trisaccharide Man(3,6)Man-OMe.

\section{Results and discussion}

Cluster compound $\mathbf{2}$ could be prepared from the condensation of 6-thio-trimannoside 1, a bifunctional amino ethanethiol linker 3, and 1,3,5-benzenetricarbonyl chloride $\mathbf{4}$, as depicted in Scheme 1.
The key 6-thiolated trisaccharide monomer $\mathbf{1}$ could be acquired from glycosylation of mannosyl trichloroacetimidate donor $\mathbf{5}$ and the 6-thio-mannoside acceptor 6.

We started from the synthesis of a suitable mannopyranoside acceptor, which contains a thiol on 6-position. Thus, D-mannose was treated with $\mathrm{AllOH}$ in the presence of catalytic amount of $\mathrm{AcCl}$ (Scheme 2), followed by regioselective tosylation of the primary hydroxyl group with a slight excess of $p$-toluenesulfonyl chloride in pyridine, to give tosylate $\mathbf{8}$ in $72 \%$ yield over 2 steps. Regioselective silylation of $\mathbf{8}$ with TBSCl using imidazole as base in DMF provided 2,4-diol $\mathbf{9}$ in a good yield of $71 \%{ }^{25}$ Acetylation of $\mathbf{9}$ with acetic anhydride in pyridine to block the free $\mathrm{OHs}$, followed by introduction of the thioacetate group at the 6-position using potassium thioacetate and TBAI under reflux, to afford desired 6-thioacetate derivative $\mathbf{1 0}$ in $96 \%$ yield. ${ }^{26}$ Several mild reaction conditions, such as sodium thiomethoxide, ${ }^{27}$ hydrazine hydrate, ${ }^{28}$ and cysteamine, ${ }^{29}$ were tried to selective convert AcS- to HS- in the presence of acetates. All efforts either gave disulfide $\mathbf{1 4}$ as the main product or gave very low yields of expected compound 12. Fortunately, we found that removal of acetyl from AcS- under 0.034 M of NaOMe in $\mathrm{MeOH}$ accomplished 12 in 70\% isolated yield, as well as the disulfide 14 in $21 \%$ yield under optimized reaction conditions. Building block 13 was obtained in two ways, i.e. treatment of 12 with HF-pyridine complex in DCM (79\% yield), or

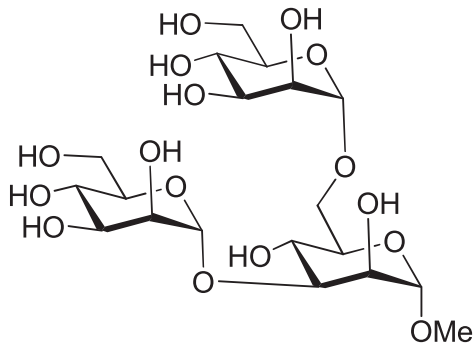

Man(3,6)Man-OMe

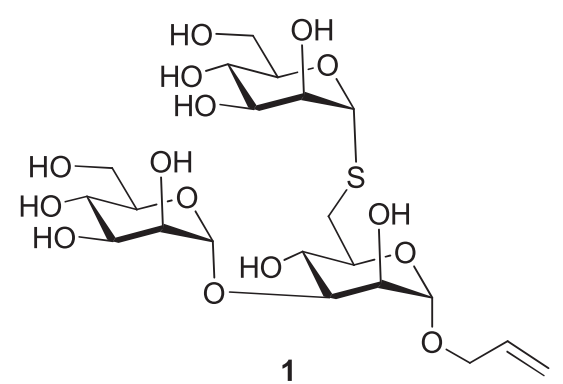

1

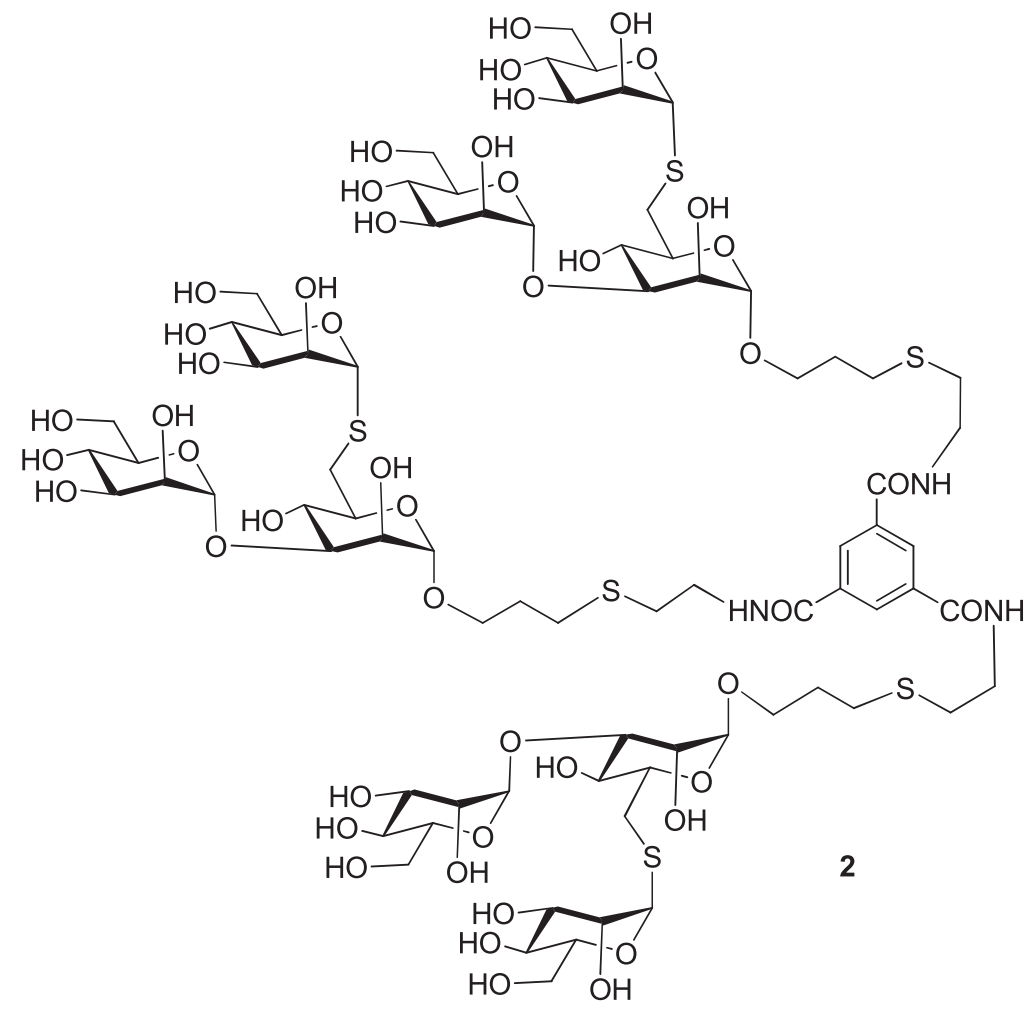

Fig. 1. Structures of methyl 3,6-di-O-( $\alpha$-D-mannopyranosyl)- $\alpha$-D-mannopyranoside, 6 -thio-trimannoside $\mathbf{1}$, and the trivalent cluster $\mathbf{2}$. 


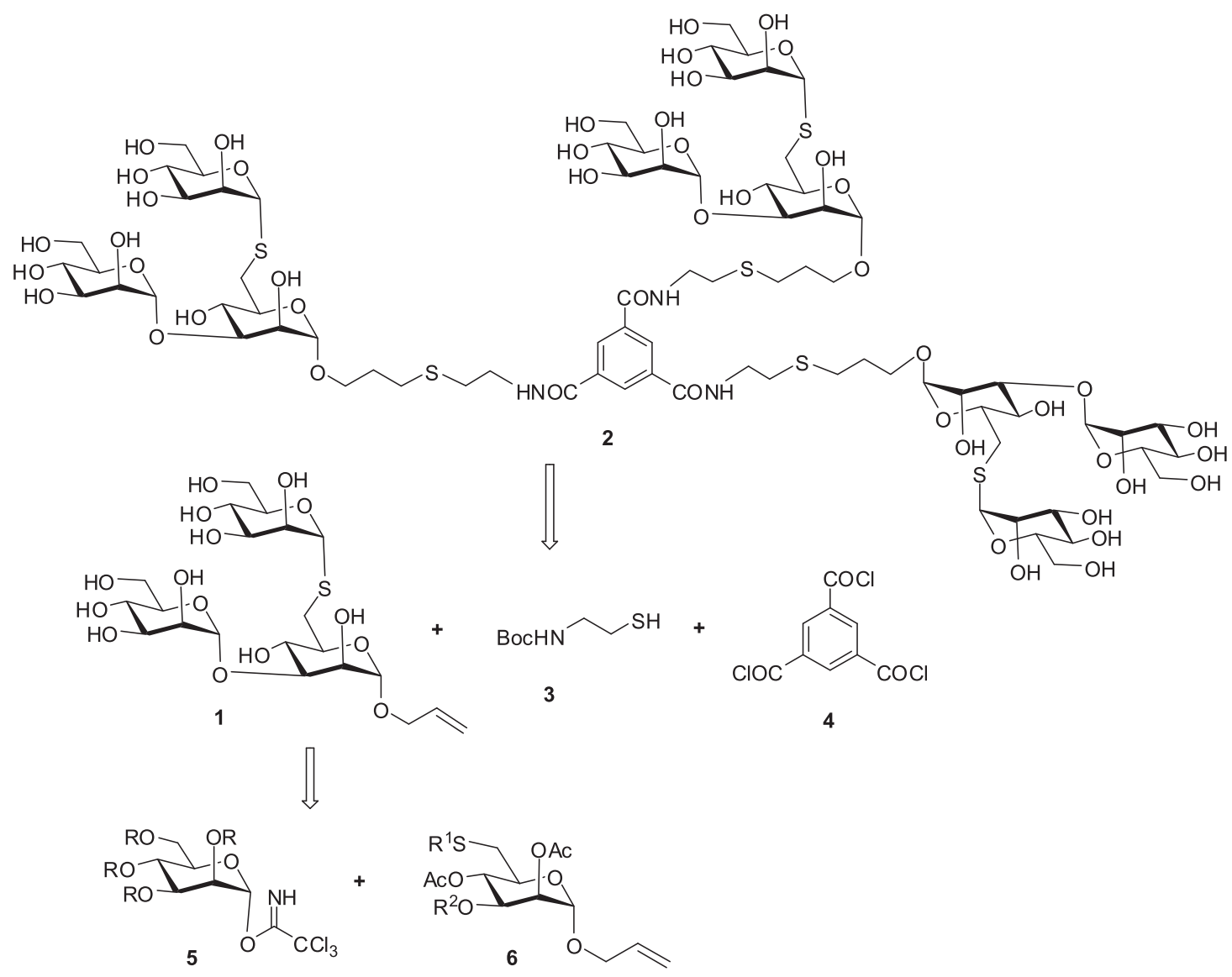

Scheme 1. Retrosynthetic analysis of 6-thio-trimannoside $\mathbf{1}$ and cluster compound $\mathbf{2}$.
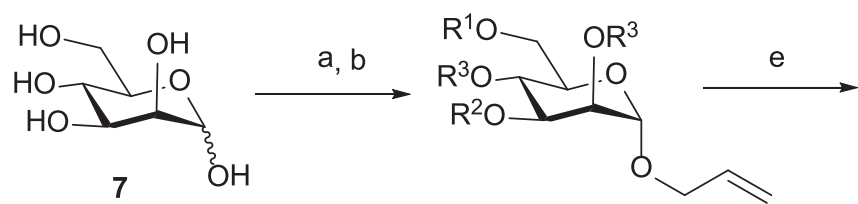

$\mathrm{C}$

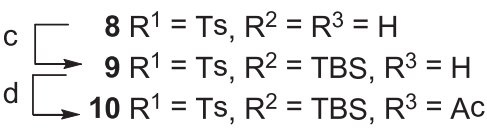

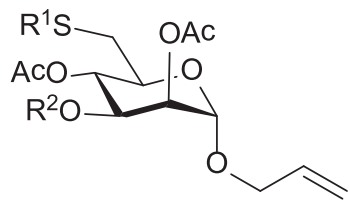

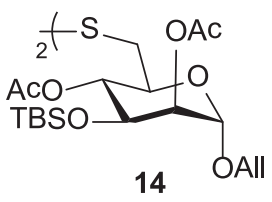

$$
\begin{aligned}
& \mathrm{f} \square 11 \mathrm{R}^{1}=\mathrm{Ac}, \mathrm{R}^{2}=\mathrm{TBS} \\
& \mathrm{g} \longrightarrow 12 \mathrm{R}^{1}=\mathrm{H}, \mathrm{R}^{2}=\mathrm{TBS} \\
& \mathrm{1} 13 \mathrm{R}^{1}=\mathrm{R}^{2}=\mathrm{H}
\end{aligned}
$$

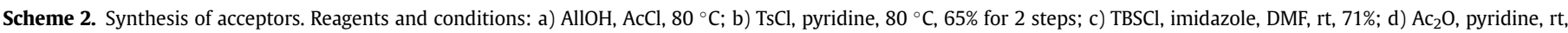
95\%; e) KSAc, $\mathrm{NBu}_{4} \mathrm{I}$, acetone, reflux, $96 \%$; f) $\mathrm{NaOMe}\left(0.034 \mathrm{M}\right.$ in $\mathrm{MeOH}$ ), $70 \%$ for 12 ; $21 \%$ for disulfide 14 ; g) $\mathrm{HF}_{-} \mathrm{pyridine} \mathrm{CH}_{2} \mathrm{Cl}_{2}, \mathrm{rt}, 79 \%$.

transformation of $\mathbf{1 4}$ with $\mathrm{n}-\mathrm{Bu}_{3} \mathrm{P}^{30}$ and then HF-pyridine in one-pot two-step reaction (70\% overall yield).

With the acceptors $\mathbf{1 2}$ and $\mathbf{1 3}$ in hand, we first examined the glycosylation of $\mathbf{1 3}$ with acetylated mannosyl trichloroacetimidate 15, expecting to afford thiomannotrioside in one-pot. However, the reaction was sluggish and no satisfactory result was obtained. Therefore, the coupling of $\mathbf{1 5}$ with acceptor $\mathbf{1 2}$ was investigated (Scheme 3). Treatment of $\mathbf{1 5}$ with $\mathbf{1 2}$ (1.5 equiv) in the presence of catalytic amount of TMSOTf ( 0.1 equiv) and $4 \AA$ molecular sieves in dry dichloromethane at $-78{ }^{\circ} \mathrm{C}$ afforded $(1 \rightarrow 6)$-S-linked disaccharide 16 and its $\beta$-isomer $18(\alpha / \beta=8 / 1)$ in $89 \%$ total yield. The chemical structure and the isomeric ratio of the disaccharides were determined based on 2D NMR spectra analyses. When the reaction was carried out at higher temperature, such as $0{ }^{\circ} \mathrm{C}$, the $\alpha / \beta$ ratio was swift to $3 / 1$ with a total yield of $92 \%$. Removal of $t$-butyldimethylsilyl group from 16 using HF-pyridine furnished disaccharide acceptor 17 in good yield without the migration of acetyl group. ${ }^{31}$ However, coupling of disaccharide acceptor $\mathbf{1 7}$ with donor $\mathbf{1 5}$ was really frustrating, as some components in the reaction mixture gave the same $R_{f}$ value on TLC, arising difficulties in products separation. Alternatively, glycosylation of benzoylated trichloroacetimidate donor $\mathbf{1 9}^{32}$ with disaccharide $\mathbf{1 7}$ was explored. The desired trisaccharide $\mathbf{2 0}$ was afforded in 66\% yield under the promotion of TMSOTf at $-78^{\circ} \mathrm{C}$. Removal of the TBS with HF-pyridine in DCM $(\rightarrow \mathbf{2 1})$ and the acyl groups with $\mathrm{NaOMe}$ in $\mathrm{MeOH}$ produced 6-thio-trimannoside $\mathbf{1}$ in excellent yield over two steps.

To synthesize cluster 2, (see Scheme 4) cysteamine and 1,3,5benzenetricarbonyl were chosen as the linker and the core, respectively. Radical addition of the Boc-protected aminoethanethiol $\mathbf{3}$ to the allyl glycoside $\mathbf{2 0}$ was carried out smoothly using $\alpha$-azobisisobutyronitrile (AIBN) as a radical initiator to furnish linker-attached trisaccharide 22. ${ }^{33}$ Deprotection of TBS $(\rightarrow \mathbf{2 3}$ ), followed by in situ 
$\mathrm{ACO} O \mathrm{OAC}$
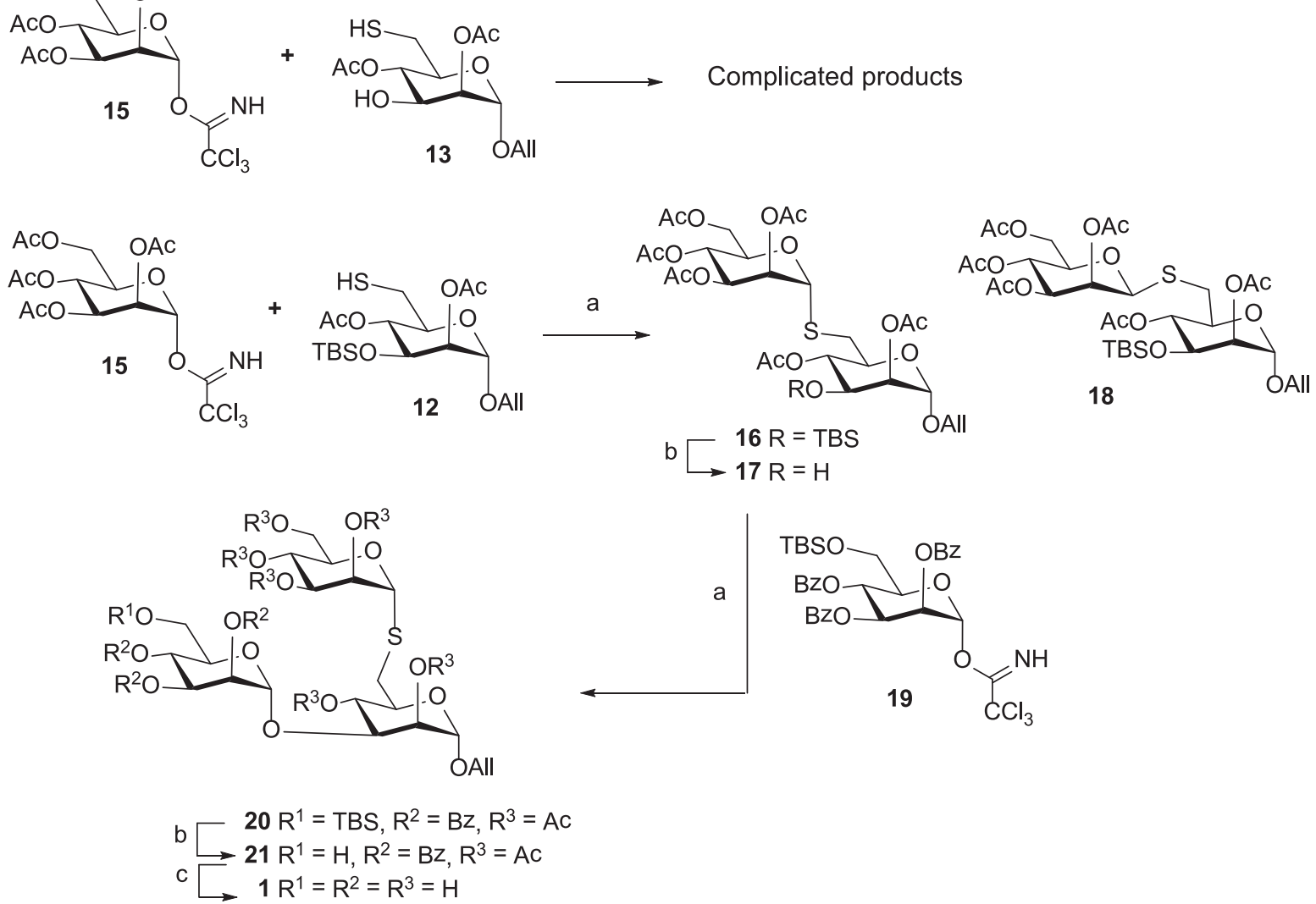

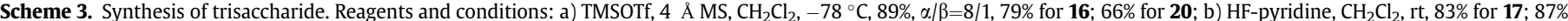
for $21 ; c)$ NaOMe $(1 \mathrm{M}), \mathrm{MeOH}$, quantitative.

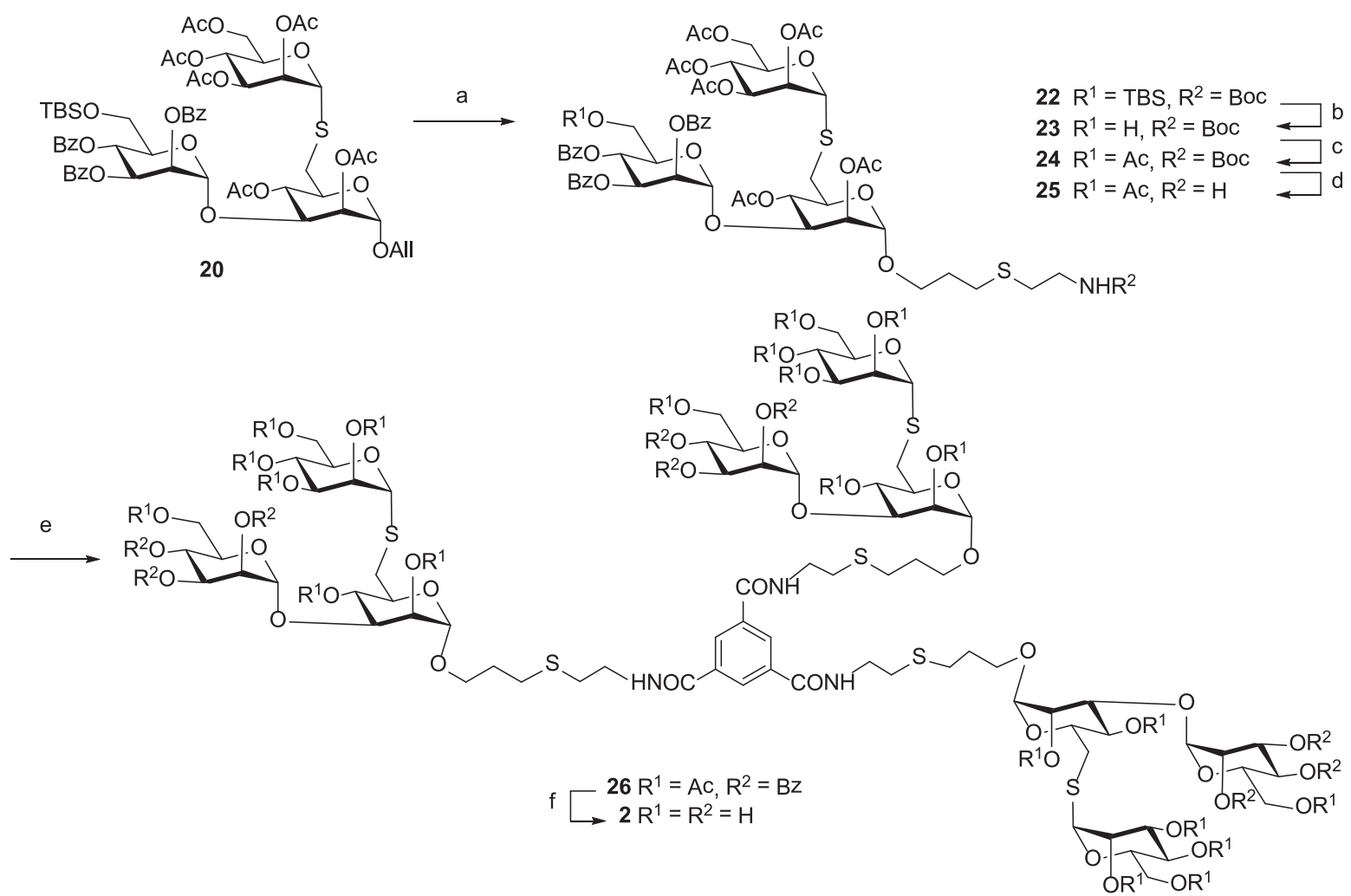

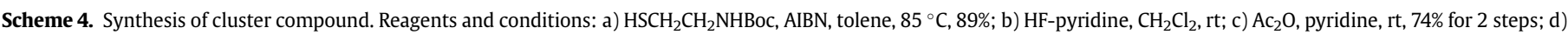
TFA, $\mathrm{CH}_{2} \mathrm{Cl}_{2}$, rt, 82\%; e) 1,3,5-benzenetricarbonyl trichloride, $\mathrm{NEt}_{3}, \mathrm{CH}_{2} \mathrm{Cl}_{2}, 0{ }^{\circ} \mathrm{C}, 67 \%$; f) $\mathrm{NaOMe}(1 \mathrm{M}), \mathrm{MeOH}$, quantitative. 
Table 1

Con A mediated hemagglutination inhibition for monomer $\mathbf{1}$ and trivalent $\mathbf{2}$ on Rabbit Erythrocytes

\begin{tabular}{ll}
\hline Inhibitor & Minimum inhibitory concentration $^{\text {a }}$ \\
\hline Man(3,6)Man-OMe $^{\text {b }}$ & $18.8 \mu \mathrm{M}$ \\
Man(3,6)Man-OAll $^{\mathrm{c}}$ & $35.8 \mu \mathrm{M}$ \\
$\mathbf{1}$ & $67.7 \mu \mathrm{M}$ \\
$\mathbf{2}$ & $18.9 \mu \mathrm{M}$ \\
\hline
\end{tabular}

${ }^{a}$ Minimum inhibitory concentrations were obtained by averaging the results of three independent experiments. The error associated with the dose determination is a factor of 2, as dictated by the 2-fold dilutions of the assay.

b Man(3,6)Man-OMe: methyl 3,6-di-O-( $\alpha$-D-mannopryranosyl)- $\alpha$-D-mannopyranoside.

c Man(3,6)Man-OAll: allyl 3,6-di-O-( $\alpha$-D-mannopryranosyl)- $\alpha$-D-mannopyranoside.

acetylation provided the compound $\mathbf{2 4}$, which was subjected to TFA in DCM afforded glycosyl amine $\mathbf{2 5}$ in good yield. Condensation of amine 25 with 1,3,5-benzenetricarbonyl trichloride $\mathbf{4}$ gave $C_{3}$-symmetric product $\mathbf{2 6}$ in the presence of TEA $^{34}$ in $67 \%$ yield, which was further deacylated to achieve the cluster compound $\mathbf{2}$ in a quantitative yield.

To fulfill our interests regarding the recognition of S-glycosyl mannotriose binding to Con A, as well as the cluster efficacy of the trivalent oligosaccharide $\mathbf{2}$, we performed a hemagglutination assay on compounds $\mathbf{1}$ and $\mathbf{2}$ to determine the relative affinities toward Con A. ${ }^{35,36}$ The binding activities of 6-thio-trimannoside monomer $\mathbf{1}$ and the trivalent derivative $\mathbf{2}$ with Con A was tested and showed in Table 1 with Man(3,6)Man-OMe as a control. Our results showed that the trivalent derivative $\mathbf{2}$ presented a comparable minimum inhibitory concentration to that of natural trimannose Man(3,6)Man-OMe, while 6-thio-trimannoside 1 showed a 3.6-fold loss in relative affinity.

To get a further insight on intermolecular interaction between trimannose and Con A, computational study was performed with Surflex, which was implemented in the Sybyl software. The 3D structure of Con A was downloaded from PDB entry 10NA. Three inhibitors were docked into the same active site of 1ONA. To verify the docking parameters, the trimannose ligand Man(3,6)Man-OMe of 10NA structure was removed from the binding site and redocked into the sugar binding site. The root mean square deviation (RMSD_ISO) between the best docking conformation of the trimannose and the X-ray crystallographic conformation was $0.53 \AA$, which indicated that the docking result was reliable and the parameters used here were adequate.

As shown in Fig. 2, all the three trimannoses could be docked into the active cite of Con A. Consistent with the previous reports, ${ }^{37-39}$ the binding interactions of $\operatorname{Man}(3,6)$ Man-OMe, Man(3,6)Man-OAll, and compound 1 with Con A were quite similar, mainly contributed from the formation of hydrogen bonds with residues (PRO13, ASN14, THR15, ASP16, LEU99, TYR100, ASP208, and ARG228) around the active site (Table 2). The scores indicated that they showed comparable bioactivities. Furthermore, crystal water molecule (WAT 259) in the active site connected the core mannose unit with the Con A residues ASN14, ASP16, and ARG228 (A and C in Fig. 2).

\section{Conclusion}

In summary, we have successfully synthesized a trimannoside monomer 1, which contains 6-thio-mannosyl residue in 11 convergent steps from D-mannose with $11 \%$ overall yield. Using cysteamine and 1,3,5-benzenetricarbonyl as the linker and the core, a trivalent oligosaccharide $\mathbf{2}$ was accomplished in a further 6 steps and in $36.2 \%$ overall yield from the corresponding fully protected trisaccharide intermediate $\mathbf{2 0}$. The bioassay revealed that the trivalent 2 possessed the similar inhibitory potency as that of the parent O-trimannoside, but 6-thio-trimannoside $\mathbf{1}$ showed a slight loss with respect to binding affinity to Con A. Computational results suggested that replacing of $\mathrm{O}$-glycoside with $\mathrm{S}$-glycoside in trimannose structure had very little effect on binding abilities between mannosyl residues and Con A.

\section{Experimental}

\subsection{General methods}

All chemicals were obtained from commercial suppliers and used without further purification unless stated. All moisture sensitive reactions were carried out in a flame dried flask under a nitrogen atmosphere. Anhydrous solvents were purified according to standard procedures before use. Column chromatography was carried out using silica gel (100-200 mesh). Reactions were monitored by silica gel $60 \mathrm{~F}_{254}$ TLC plates and/or by charring following immersion in a $30 \%$ sulfuric acid in methanol. ${ }^{1} \mathrm{H}$ and ${ }^{13} \mathrm{C}$ NMR spectra were measured with a Bruker AVANCE-III $400 \mathrm{MHz}$ (100 MHz for ${ }^{13} \mathrm{C}$ NMR) spectrometer. High resolution mass spectra (HRMS) were recorded with a Bruker microTOF Q II mass spectrometer. Optical rotations were measured with a Rudolph Research Analytical Autopol ${ }^{\circledR}$ VI automatic digital polarimeter.

\subsection{Allyl 6-O-tosyl- $\alpha$-D-mannopyranoside (8)}

D-Mannose (20 g, $111 \mathrm{mmol}$ ) was refluxed for $4 \mathrm{~h}$ in AllOH $(200 \mathrm{~mL})$ in the presence of $\mathrm{AcCl}(0.42 \mathrm{~mL}, 5.6 \mathrm{mmol})$. After neutralization with $\mathrm{NEt}_{3}$, the allyl alcohol was removed by evaporation, and the residue was subjected to flash column chromatography (ethyl acetate/MeOH=10:1) to afford allyl mannopyranoside as a syrup. To the above syrup in pyridine $(200 \mathrm{~mL})$ was added slowly $p$ - $\mathrm{TsCl}(22.6 \mathrm{~g}, 118 \mathrm{mmol})$ in several portions at $0{ }^{\circ} \mathrm{C}$. The reaction mixture was stirred at $\mathrm{rt}$ for $18 \mathrm{~h}$. The solvent was removed by evaporation, and column chromatography of the residue on silica gel (EtOAc/MeOH, 100:1) afforded 8 (26.9 g, 65\% over two

Table 2

Hydrogen bonds and total scores for the combination of Con A and trimannose residues

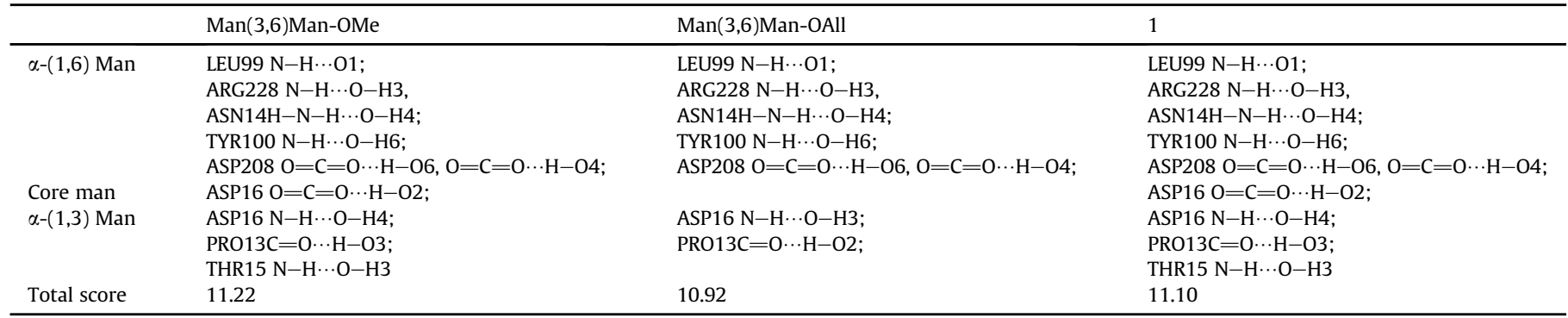




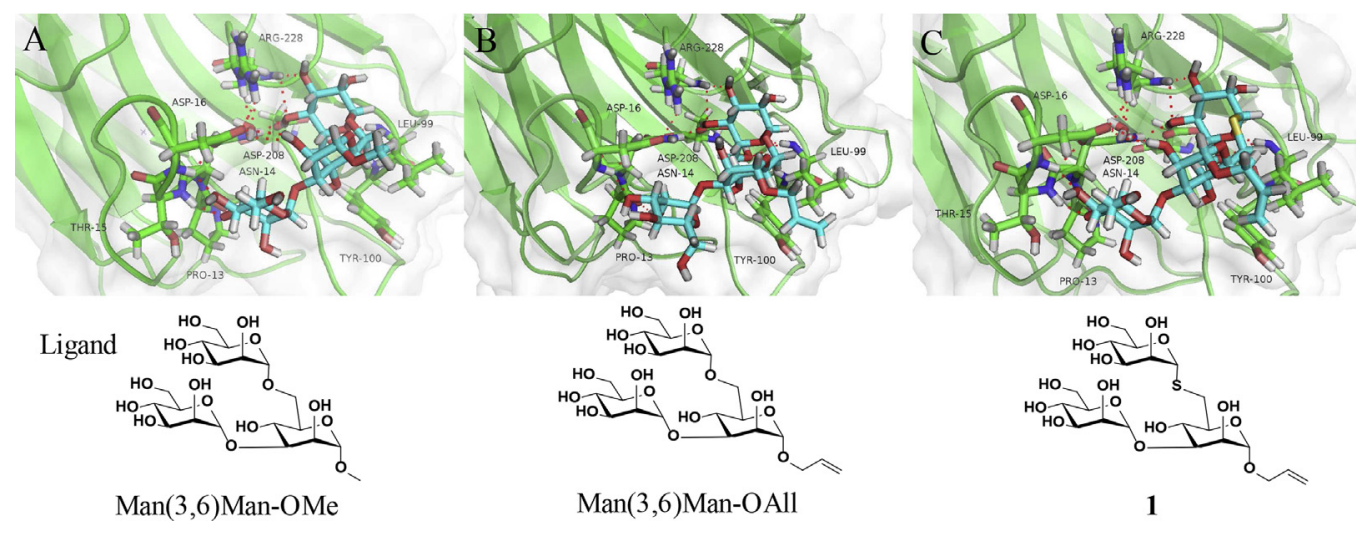

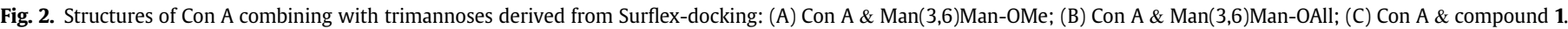

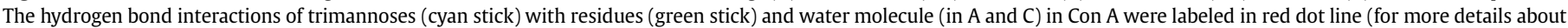
hydrogen bond information, see Table 2).(For interpretation of the references to colour in this figure legend, the reader is referred to the web version of this article.)

steps) as a syrup. $[\alpha]_{\mathrm{D}}^{25}+30.1\left(\mathrm{c} 2.1, \mathrm{CH}_{3} \mathrm{OH}\right) ;{ }^{1} \mathrm{H}$ NMR $(400 \mathrm{MHz}$ $\left.\mathrm{CDCl}_{3}\right): \delta 7.79(\mathrm{~d}, J=8.0 \mathrm{~Hz}, 2 \mathrm{H}), 7.31(\mathrm{~d}, J=8.0 \mathrm{~Hz}, 2 \mathrm{H}), 5.84-5.80(\mathrm{~m}$, $1 \mathrm{H}, \mathrm{CH}_{2} \mathrm{CH}=\mathrm{CH}_{2}$ ), 5.23 (dd, $J=17.2,1.4 \mathrm{~Hz}, 1 \mathrm{H}, \mathrm{CH}_{2} \mathrm{CH}=\mathrm{CH}_{2}$ ), 5.15 (dd, $\left.J=10.4,1.4 \mathrm{~Hz}, 1 \mathrm{H}, \mathrm{CH}_{2} \mathrm{CH}=\mathrm{CH}_{2}\right), 4.80(\mathrm{~s}, 1 \mathrm{H}, \mathrm{H}-1), 4.41$ (d, $J=5.2 \mathrm{~Hz}, 1 \mathrm{H}, \mathrm{H}-2), 4.33(\mathrm{dd}, J=10.0,3.6 \mathrm{~Hz}, 1 \mathrm{H}, \mathrm{H}-3), 4.28(\mathrm{t}$, $J=10.4 \mathrm{~Hz}, 1 \mathrm{H}, \mathrm{H}-4), 4.20$ (s, $1 \mathrm{H}, \mathrm{OH}), 4.07$ (dd, $J=12.8,5.2 \mathrm{~Hz}, 1 \mathrm{H}$, $\left.\mathrm{CH}_{2} \mathrm{CH}=\mathrm{CH}_{2}\right), 3.94-3.87\left(\mathrm{~m}, 3 \mathrm{H}, \mathrm{H}-5, \mathrm{OH}, \mathrm{CH}_{2} \mathrm{CH}=\mathrm{CH}_{2}\right), 3.80(\mathrm{~s}$, $1 \mathrm{H}, \mathrm{OH}$ ), 3.77-3.71 (m, 2H, H-6a,b), 2.41 (s, 3H) ppm; ${ }^{13} \mathrm{C}$ NMR $\left(100 \mathrm{MHz}, \mathrm{CDCl}_{3}\right): \delta 145.1,133.9,133.0,129.7(2), 127.7(2), 116.1,99.3$, 71.1, 70.9, 70.5, 70.0, 67.6, 66.8, 20.2 ppm; HRMS (ESI) $\mathrm{m} / z$ calcd for $\mathrm{C}_{16} \mathrm{H}_{22} \mathrm{O}_{8} \mathrm{SNa}[\mathrm{M}+\mathrm{Na}]^{+}$397.0933, found $m / z$ 397.0950.

\subsection{Allyl 3-O-t-butyldimethylsilyl-6-O-tosyl- $\alpha$-D-mannopyranoside} (9)

To a mixture of compound 8 (4 g, $10.7 \mathrm{mmol}$ ) in $\mathrm{N}, \mathrm{N}$ dimethylformamide $(10 \mathrm{~mL})$ was added TBSCl $(1.62 \mathrm{~g}, 10.7 \mathrm{mmol})$ and imidazole $(0.801 \mathrm{~g}, 11.77 \mathrm{mmol})$ at $0{ }^{\circ} \mathrm{C}$. The reaction mixture was stirred under this condition for $30 \mathrm{~min}$, and kept at rt overnight, then diluted with water $(50 \mathrm{~mL})$ and extracted with EtOAc $(3 \times 100 \mathrm{~mL})$. The organic phase was dried over anhydrous $\mathrm{Na}_{2} \mathrm{SO}_{4}$ and concentrated. Purification of the residue by column chromatography (petroleum ether/EtOAc $=5 / 1)$ afforded $\mathbf{9}(3.7 \mathrm{~g}, 71 \%)$ as colorless oil. $[\alpha]_{\mathrm{D}}^{25}+41.9\left(\right.$ c $\left.2.4, \mathrm{CHCl}_{3}\right) ;{ }^{1} \mathrm{H} \mathrm{NMR}\left(400 \mathrm{MHz}, \mathrm{CDCl}_{3}\right)$ : $\delta 7.78(\mathrm{~d}, J=8.0 \mathrm{~Hz}, 2 \mathrm{H}), 7.31(\mathrm{~d}, J=8.0 \mathrm{~Hz}, 2 \mathrm{H}), 5.85-5.81(\mathrm{~m}, 1 \mathrm{H}$, $\mathrm{CH}_{2} \mathrm{CH}=\mathrm{CH}_{2}$ ), 5.22 (dd, $J=17.2,1.2 \mathrm{~Hz}, 1 \mathrm{H}, \mathrm{CH}_{2} \mathrm{CH}=\mathrm{CH}_{2}$ ), 5.16 (dd, $\left.J=10.4,1.2 \mathrm{~Hz}, 1 \mathrm{H}, \mathrm{CH}_{2} \mathrm{CH}=\mathrm{CH}_{2}\right), 4.81(\mathrm{~s}, 1 \mathrm{H}, \mathrm{H}-1), 4.32-4.24(\mathrm{~m}$, $2 \mathrm{H}, \mathrm{H}-2, \mathrm{H}-4$ ), 4.08 (dd, $J=13.2,5.2 \mathrm{~Hz}, 1 \mathrm{H}, \mathrm{CH}_{2} \mathrm{CH}=\mathrm{CH}_{2}$ ), 3.90 (dd, $\left.J=12.8,6.0 \mathrm{~Hz}, 1 \mathrm{H}, \mathrm{CH}_{2} \mathrm{CH}=\mathrm{CH}_{2}\right), 3.83(\mathrm{dd}, J=8.4,3.2 \mathrm{~Hz}, 1 \mathrm{H}, \mathrm{H}-3$ ), 3.76-3.65 (m, 3H, H-5, H-6a,b), 2.55 (s, 1H, OH), 2.42 (s, 3H, OAc), $2.35(\mathrm{~d}, J=4.0 \mathrm{~Hz}, 1 \mathrm{H}, \mathrm{OH}), 0.89\left(\mathrm{~s}, 9 \mathrm{H}, \mathrm{C}\left(\mathrm{CH}_{3}\right)_{3}\right), 0.11(\mathrm{~s}, 3 \mathrm{H}$, $\left.\mathrm{Si}\left(\mathrm{CH}_{3}\right)_{2}\right), 0.05$ (s, 3H, Si $\left.\left(\mathrm{CH}_{3}\right)_{2}\right) \mathrm{ppm} ;{ }^{13} \mathrm{C} \mathrm{NMR}\left(100 \mathrm{MHz}, \mathrm{CDCl}_{3}\right)$ : $\delta$ 144.8, 133.5, 132.9, 129.8(2), 128.0(2), 117.6, 98.2, 73.0, 71.3, 69.9, $69.4,68.0,67.3,25.8(3), 21.6,18.1,-4.5,-4.7 \mathrm{ppm}$; HRMS (ESI) $\mathrm{m} / z$ calcd for $\mathrm{C}_{22} \mathrm{H}_{36} \mathrm{O}_{8} \mathrm{SSiNa}[\mathrm{M}+\mathrm{Na}]^{+} 511.1798$, found $\mathrm{m} / z$ 511.1815.

\subsection{Allyl 2,4-di-O-acetyl-3-O-t-butyldimethylsilyl-6-O-tosyl- $\alpha-D-$ mannopyranoside (10)}

To a solution of $\mathbf{9}(3.0 \mathrm{~g}, 6.15 \mathrm{mmol})$ in pyridine $(10 \mathrm{~mL})$ was added $\mathrm{Ac}_{2} \mathrm{O}$ ( $\left.1.34 \mathrm{~mL}, 14.1 \mathrm{mmol}\right)$. The reaction mixture was stirred at $\mathrm{rt}$ for $2 \mathrm{~h}$ and then evaporated under vacuo to give a yellow oil. It was purified by silica gel column chromatography (petroleum ether/EtOAc $=6 / 1)$ to give $\mathbf{1 0}(3.33 \mathrm{~g}, 95 \%)$ as colorless oil. $[\alpha]_{\mathrm{D}}^{25}+29.6\left(\mathrm{c} 2.1, \mathrm{CHCl}_{3}\right) ;{ }^{1} \mathrm{H}$ NMR $\left(400 \mathrm{MHz}, \mathrm{CDCl}_{3}\right): \delta 7.78(\mathrm{~d}$,
$J=8.0 \mathrm{~Hz}, 2 \mathrm{H}), 7.34(\mathrm{~d}, J=8.0 \mathrm{~Hz}, 2 \mathrm{H}), 5.89-5.85\left(\mathrm{~m}, 1 \mathrm{H}, \mathrm{CH}_{2} \mathrm{CH}=\right.$ $\mathrm{CH}_{2}$ ), 5.27 (d, $\left.J=17.2 \mathrm{~Hz}, 1 \mathrm{H}, \mathrm{CH}_{2} \mathrm{CH}=\mathrm{CH}_{2}\right), 5.22(\mathrm{~d}, J=10.0 \mathrm{~Hz}, 1 \mathrm{H}$, $\left.\mathrm{CH}_{2} \mathrm{CH}=\mathrm{CH}_{2}\right), 5.06(\mathrm{~d}, J=1.6 \mathrm{~Hz}, 1 \mathrm{H}, \mathrm{H}-2), 4.98(\mathrm{t}, J=9.6 \mathrm{~Hz}, 1 \mathrm{H}, \mathrm{H}-4)$, $4.72(\mathrm{~s}, 1 \mathrm{H}, \mathrm{H}-1), 4.15-4.05\left(\mathrm{~m}, 4 \mathrm{H}, \mathrm{CH}_{2} \mathrm{CH}=\mathrm{CH}_{2}, \mathrm{H}-3, \mathrm{H}-6 \mathrm{a}, \mathrm{b}\right)$, 3.96-3.90 (m, $\left.2 \mathrm{H}, \mathrm{H}-5, \mathrm{CH}_{2} \mathrm{CH}=\mathrm{CH}_{2}\right), 2.44\left(\mathrm{~s}, 3 \mathrm{H}, \mathrm{CH}_{3}\right), 2.08(\mathrm{~s}, 3 \mathrm{H}$, $\mathrm{OAc}$ ), 2.03 (s, 3H, OAc), $0.80\left(\mathrm{~s}, 9 \mathrm{H}, \mathrm{C}\left(\mathrm{CH}_{3}\right)_{3}\right), 0.05\left(\mathrm{~s}, 3 \mathrm{H}, \mathrm{Si}\left(\mathrm{CH}_{3}\right)_{2}\right)$, 0.03 (s, 3H, Si $\left.\left(\mathrm{CH}_{3}\right)_{2}\right) \mathrm{ppm} ;{ }^{13} \mathrm{C} \mathrm{NMR}\left(100 \mathrm{MHz}, \mathrm{CDCl}_{3}\right): \delta 170.2$, 169.9, 144.9, 133.1, 132.8, 129.8(2), 128.1(2), 118.2, 96.6, 71.7, 69.4. 69.1, 68.8, 68.4, 68.1, 25.4(3), 21.7, 21.0, 20.9, 17.7, -4.8, -5.1 ppm; HRMS (ESI) $m / z$ calcd for $\mathrm{C}_{26} \mathrm{H}_{40} \mathrm{O}_{10} \mathrm{SSiNa}[\mathrm{M}+\mathrm{Na}]^{+} 595.2009$, found 595.2020 .

\subsection{Allyl 2,4-di-O-acetyl-3-O-t-butyldimethylsilyl-6-S-acetyl- $\alpha-D$ - mannopyranoside (11)}

A solution of $\mathbf{1 0}$ (2.5 g, $4.37 \mathrm{mmol})$, KSAc (2.7 g, $23.5 \mathrm{mmol})$, and a catalytic amount of $\mathrm{NBu}_{4} \mathrm{I}$ in acetone $(20 \mathrm{~mL})$ was refluxed for $6 \mathrm{~h}$. At the end of which time, the mixture was diluted with EtOAc $(40 \mathrm{~mL})$ and washed with $\mathrm{H}_{2} \mathrm{O}(2 \times 25 \mathrm{~mL})$. The organic layer was dried over $\mathrm{Na}_{2} \mathrm{SO}_{4}$, concentrated in vacuo, and the syrup was purified by flash column chromatography (petroleum ether/ EtOAc $=12 / 1)$, to yield $\mathbf{1 1}(2 \mathrm{~g}, 96 \%)$ as light red oil. $[\alpha]_{\mathrm{D}}^{25}+34.4(\mathrm{c} 1.0$, $\left.\mathrm{CHCl}_{3}\right) ;{ }^{1} \mathrm{H}$ NMR $\left(400 \mathrm{MHz}, \mathrm{CDCl}_{3}\right): \delta 5.90-5.85\left(\mathrm{~m}, 1 \mathrm{H}, \mathrm{CH}_{2} \mathrm{CH}=\right.$ $\mathrm{CH}_{2}$ ), 5.28 (dd, $J=17.2,1.2 \mathrm{~Hz}, 1 \mathrm{H}, \mathrm{CH}_{2} \mathrm{CH}=\mathrm{CH}_{2}$ ), 5.22 (dd, $J=10.4$, $\left.1.2 \mathrm{~Hz}, 1 \mathrm{H}, \mathrm{CH}_{2} \mathrm{CH}=\mathrm{CH}_{2}\right), 5.09-5.05(\mathrm{~m}, 2 \mathrm{H}, \mathrm{H}-2, \mathrm{H}-4), 4.74(\mathrm{~s}, 1 \mathrm{H}$, $\mathrm{H}-1$ ), 4.16 (dd, $J=12.8,5.2 \mathrm{~Hz}, 1 \mathrm{H}, \mathrm{CH}_{2} \mathrm{CH}=\mathrm{CH}_{2}$ ), 4.07 (dd, $J=9.2$, $3.6 \mathrm{~Hz}, 1 \mathrm{H}, \mathrm{H}-3$ ), 3.96 (dd, $\left.J=12.8,6.0 \mathrm{~Hz}, 1 \mathrm{H}, \mathrm{CH}_{2} \mathrm{CH}=\mathrm{CH}_{2}\right), 3.72(\mathrm{dt}$, $J=9.2,2.4 \mathrm{~Hz}, 1 \mathrm{H}, \mathrm{H}-5$ ), 3.27 (dd, $J=14.0,2.8 \mathrm{~Hz}, 1 \mathrm{H}, \mathrm{H}-6 \mathrm{a}$ ), 2.89 (dd, $J=14.0,8.8 \mathrm{~Hz}, 1 \mathrm{H}, \mathrm{H}-6 \mathrm{~b}), 2.34$ (s, 3H, OAc), 2.13 (s, 3H, OAc), 2.11 (s, $3 \mathrm{H}, \mathrm{OAc}), 0.81$ (s, 9H, C( $\left.\left.\mathrm{CH}_{3}\right)_{3}\right), 0.05\left(\mathrm{~s}, 3 \mathrm{H}, \mathrm{Si}\left(\mathrm{CH}_{3}\right)_{2}\right), 0.04(\mathrm{~s}, 3 \mathrm{H}$, $\left.\mathrm{Si}\left(\mathrm{CH}_{3}\right)_{2}\right) \mathrm{ppm} ;{ }^{13} \mathrm{C} \mathrm{NMR}\left(100 \mathrm{MHz}, \mathrm{CDCl}_{3}\right): \delta 195.0,170.3,170.1$, 133.2, 118.1, 96.6, 71.9, 71.8, 70.3, 68.2, 68.1, 30.7, 30.5, 25.4(3), 21.2, 21.0, 17.7, $-4.8,-5.1 \mathrm{ppm}$; HRMS (ESI) $m / z$ calcd for $\mathrm{C}_{21} \mathrm{H}_{36} \mathrm{O}_{8} \mathrm{SSiNa}$ $[\mathrm{M}+\mathrm{Na}]^{+}$499.1798, found 499.1768 .

\subsection{Allyl 2,4-di-O-acetyl-3-O-t-butyldimethylsilyl-6-thio- $\alpha-D-$ mannopyranoside (12)}

To a stirred solution of sodium methoxide $(0.034 \mathrm{M}$ in $\mathrm{MeOH}$, $85 \mathrm{~mL}$ ) was added 11 ( $1.38 \mathrm{~g}, 2.90 \mathrm{mmol}$ ) under nitrogen protection. The reaction mixture was stirred at $\mathrm{rt}$ for $2 \mathrm{~h}$ and amberlite IR-120 $\left(\mathrm{H}^{+}\right)$was added to neutralize when $\mathbf{1 1}$ was consumed completely (TLC), filtered and evaporated in vacuo. The mixture was purified by flash chromatography (petroleum ether/EtOAc $=15 / 1$ ) to yield 12 (881 mg, 70\%) and disulfide 14 (263 mg, 21\%). For 12, $[\alpha]_{\mathrm{D}}^{25}+47.1(c$ 
2.3, $\left.\mathrm{CHCl}_{3}\right) ;{ }^{1} \mathrm{H}$ NMR (400 $\left.\mathrm{MHz}, \mathrm{CDCl}_{3}\right): \delta$ 5.91-5.87 (m, $1 \mathrm{H}$, $\mathrm{CH}_{2} \mathrm{CH}=\mathrm{CH}_{2}$ ), 5.28 (dd, $J=17.2,1.4 \mathrm{~Hz}, 1 \mathrm{H}, \mathrm{CH}_{2} \mathrm{CH}=\mathrm{CH}_{2}$ ), 5.21 (dd, $J=10.4,1.4 \mathrm{~Hz}, 1 \mathrm{H}, \mathrm{CH}_{2} \mathrm{CH}=\mathrm{CH}_{2}$ ), 5.08 (dd, $J=3.6,1.6 \mathrm{~Hz}, 1 \mathrm{H}, \mathrm{H}-2$ ), 5.03 (t, $J=9.6 \mathrm{~Hz}, 1 \mathrm{H}, \mathrm{H}-4), 4.77$ (d, $J=1.2 \mathrm{~Hz}, 1 \mathrm{H}, \mathrm{H}-1$ ), 4.23 (dd, $J=12.8,5.2 \mathrm{~Hz}, 1 \mathrm{H}, \mathrm{CH}_{2} \mathrm{CH}=\mathrm{CH}_{2}$ ), 4.07 (dd, $J=9.6,3.6 \mathrm{~Hz}, 1 \mathrm{H}, \mathrm{H}-3$ ), 4.00 (dd, $J=12.8,6.0 \mathrm{~Hz}, 1 \mathrm{H}, \mathrm{CH}_{2} \mathrm{CH}=\mathrm{CH}_{2}$ ), 3.69 (dt, $J=9.2,2.4 \mathrm{~Hz}$, 1H, H-5), 2.71-2.64 (m, 1H, H-6a), 2.55-2.48 (m, 1H, H-6b), 2.09 (s, $3 \mathrm{H}, \mathrm{OAc}), 2.05$ (s, 3H, OAc), 1.75 (dd, $J=10.4,6.0 \mathrm{~Hz}, 1 \mathrm{H}, \mathrm{SH}), 0.79$ (s, 9H, $\left.\mathrm{C}\left(\mathrm{CH}_{3}\right)_{3}\right), 0.04\left(\mathrm{~s}, 3 \mathrm{H}, \mathrm{Si}\left(\mathrm{CH}_{3}\right)_{2}\right), 0.03\left(\mathrm{~s}, 3 \mathrm{H}, \mathrm{Si}\left(\mathrm{CH}_{3}\right)_{2}\right) \mathrm{ppm} ;{ }^{13} \mathrm{C}$ NMR (100 MHz, $\left.\mathrm{CDCl}_{3}\right): \delta$ 170.3, 169.9, 133.3, 118.0, 96.5, 72.1, 71.9, 71.5, 68.3, 68.2, 26.4, 25.4(3), 21.1, 20.9, 17.7, -4.8, -5.1 ppm; HRMS (ESI) $\mathrm{m} / \mathrm{z}$ calcd for $\mathrm{C}_{19} \mathrm{H}_{34} \mathrm{O}_{7} \mathrm{SSiNa}[\mathrm{M}+\mathrm{Na}]^{+} 457.1692$, found 457.1709. For 14, $[\alpha]_{\mathrm{D}}^{25}+102.8\left(\right.$ c 1.2, $\left.\mathrm{CHCl}_{3}\right) ;{ }^{1} \mathrm{H}$ NMR $(400 \mathrm{MHz}$, $\left.\mathrm{CDCl}_{3}\right): \delta 5.91-5.87\left(\mathrm{~m}, 1 \mathrm{H}, \mathrm{CH}_{2} \mathrm{CH}=\mathrm{CH}_{2}\right), 5.31(\mathrm{dd}, J=17.2,1.4 \mathrm{~Hz}$, $2 \mathrm{H}, \mathrm{CH}_{2} \mathrm{CH}=\mathrm{CH}_{2}$ ), $5.22\left(\mathrm{dd}, \mathrm{J}=10.0,1.4 \mathrm{~Hz}, 2 \mathrm{H}, \mathrm{CH}_{2} \mathrm{CH}=\mathrm{CH}_{2}\right), 5.10$ (dd, $J=3.6,1.2 \mathrm{~Hz}, 2 \mathrm{H}, \mathrm{H}-2$ ), 5.02 (t, $J=9.6 \mathrm{~Hz}, 2 \mathrm{H}, \mathrm{H}-4), 4.77$ (d, $J=1.2 \mathrm{~Hz}, 2 \mathrm{H}, \mathrm{H}-1$ ), 4.22 (dd, $J=12.8,5.2 \mathrm{~Hz}, 2 \mathrm{H}, \mathrm{CH}_{2} \mathrm{CH}=\mathrm{CH}_{2}$ ), 4.10 (dd, $J=9.6,3.6 \mathrm{~Hz}, 2 \mathrm{H}, \mathrm{H}-3$ ), 3.99 (dd, $J=12.8,6.4 \mathrm{~Hz}, 2 \mathrm{H}, \mathrm{CH}_{2} \mathrm{CH}=$ $\mathrm{CH}_{2}$ ), 3.92 (dt, J=9.6, $2.4 \mathrm{~Hz}, 2 \mathrm{H}, \mathrm{H}-5$ ), 2.86 (dd, $J=13.6,9.6 \mathrm{~Hz}, 2 \mathrm{H}$, H-6a), 2.77 (dd, J=13.6, 2.4 Hz, 2H, H-6b), 2.10 (s, 6H, OAc), 2.09 (s, $6 \mathrm{H}, \mathrm{OAc}), 0.81\left(\mathrm{~s}, 18 \mathrm{H}, \mathrm{C}\left(\mathrm{CH}_{3}\right)_{3}\right), 0.06\left(\mathrm{~s}, 6 \mathrm{H}, \mathrm{Si}\left(\mathrm{CH}_{3}\right)_{2}\right), 0.05(\mathrm{~s}, 6 \mathrm{H}$, $\left.\mathrm{Si}\left(\mathrm{CH}_{3}\right)_{2}\right) \mathrm{ppm} ;{ }^{13} \mathrm{C}$ NMR $\left(100 \mathrm{MHz}, \mathrm{CDCl}_{3}\right): \delta 170.3(2), 170.1(2)$, 133.2(2), 118.2(2), 96.5(2), 72.2(2), 71.9(2), 68.8(2), 68.3(4), 40.8(2), 25.4(6), 21.2(2), 20.9(2), 17.7(2), -4.8(2), -5.1(2) ppm; HRMS (ESI) $\mathrm{m} / \mathrm{z}$ calcd for $\mathrm{C}_{38} \mathrm{H}_{66} \mathrm{O}_{14} \mathrm{~S}_{2} \mathrm{Si}_{2} \mathrm{Na}[\mathrm{M}+\mathrm{Na}]^{+}$889.3330, found 866.3297.

4.7. Allyl 2,4-di-O-acetyl-3-O-t-butyldimethylsilyl-6-S-(2,3,4,6tetra-O-acetyl- $\alpha$-D-mannopyranosyl) $-\alpha-D$-mannopyranoside (16)

A mixture of 12 (700 mg, $1.61 \mathrm{mmol})$ and freshly dried $4 \AA$ molecular sieves $(400 \mathrm{mg})$ in anhydrous dichloromethane $(4 \mathrm{~mL})$ was stirred for $10 \mathrm{~min}$ under nitrogen at $-78^{\circ} \mathrm{C}$, and TMSOTf $(30 \mu \mathrm{L}$, $0.16 \mathrm{mmol}$ ) was added quickly. Then a solution of 15 (1.2 g, $2.4 \mathrm{mmol})$ in dry $\mathrm{CH}_{2} \mathrm{Cl}_{2}(3 \mathrm{~mL})$ was added dropwise. The reaction mixture was stirred at $-78{ }^{\circ} \mathrm{C}$ until TLC indicated complete conversion of the accepter 12 and then quenched with $\mathrm{Et}_{3} \mathrm{~N}(0.1 \mathrm{~mL})$. Solid was collected and wash with dichloromethane, and the filtrate was concentrated in vacuo to obtain an oily residue that was purified by silica gel column chromatography (petroleum ether/ EtOAc $=4 / 1)$ to provide the major $\alpha$-isomer $16(971 \mathrm{mg}, 79 \%)$ as a colorless syrup, as well as the $\beta$-isomer $\mathbf{1 8}(123 \mathrm{mg}, 10 \%)$. For $\mathbf{1 6}$, $[\alpha]_{\mathrm{D}}^{25}+55.1\left(\mathrm{c} 2.45, \mathrm{CHCl}_{3}\right) ;{ }^{1} \mathrm{H}$ NMR $\left(400 \mathrm{MHz}, \mathrm{CDCl}_{3}\right): \delta$ 5.91-5.87 $\left(\mathrm{m}, 1 \mathrm{H}, \mathrm{CH}_{2} \mathrm{CH}=\mathrm{CH}_{2}\right), 5.30-5.24\left(\mathrm{~m}, 5 \mathrm{H}, \mathrm{H}-1^{\prime}, \mathrm{H}-2^{\prime}, \mathrm{H}-3^{\prime}, \mathrm{H}-4^{\prime}\right.$, $\mathrm{CH}_{2} \mathrm{CH}=\mathrm{CH}_{2}$ ), 5.21 (dd, $J=10.4,1.2 \mathrm{~Hz}, 1 \mathrm{H}, \mathrm{CH}_{2} \mathrm{CH}=\mathrm{CH}_{2}$ ), 5.10-5.06 (m, 2H, H-2, H-4), 4.75 (d, J=1.2 Hz, 1H, H-1), 4.38-4.33 (m, $1 \mathrm{H}, \mathrm{H}-$ $5^{\prime}$ ), 4.29 (dd, $J=12.4,4.8 \mathrm{~Hz}, 1 \mathrm{H}, \mathrm{H}-6 \mathrm{a}^{\prime}$ ), 4.19 (dd, $J=12.8,4.8 \mathrm{~Hz}, 1 \mathrm{H}$, $\left.\mathrm{CH}_{2} \mathrm{CH}=\mathrm{CH}_{2}\right), 4.09-4.04\left(\mathrm{~m}, 2 \mathrm{H}, \mathrm{H}-3, \mathrm{H}-6 \mathrm{~b}^{\prime}\right), 3.99$ (dd, $J=12.8$, $6.0 \mathrm{~Hz}, 1 \mathrm{H}, \mathrm{CH}_{2} \mathrm{CH}=\mathrm{CH}_{2}$ ), 3.81 (dt, $J=10.0,2.8 \mathrm{~Hz}, 1 \mathrm{H}, \mathrm{H}-5$ ), 2.75 (dd, $J=14.0,3.2 \mathrm{~Hz}, 1 \mathrm{H}, \mathrm{H}-6 \mathrm{a}$ ), 2.68 (dd, $J=14.0,8.0 \mathrm{~Hz}, 1 \mathrm{H}, \mathrm{H}-6 \mathrm{~b}), 2.15$ (s, $3 \mathrm{H}, \mathrm{OAc}), 2.10$ (s, 6H, OAc), 2.05 (s, 3H, OAc), 2.03 (s, 3H, OAc), 1.97 (s, $3 \mathrm{H}, \mathrm{OAc}), 0.80$ (s, 9H, C( $\left.\left.\mathrm{CH}_{3}\right)_{3}\right), 0.05$ (s, 3H, Si $\left.\left(\mathrm{CH}_{3}\right)_{2}\right), 0.03$ (s, 3H, $\left.\mathrm{Si}\left(\mathrm{CH}_{3}\right)_{2}\right) \mathrm{ppm} ;{ }^{13} \mathrm{C} \mathrm{NMR}\left(100 \mathrm{MHz}, \mathrm{CDCl}_{3}\right): \delta$ 170.7, 170.4, 169.9, 169.8, 169.7(2), 133.2, 117.9, 96.6, 82.3, 71.8, 71.7, 70.8, 69.5, 69.4, 69.0, 68.3, 68.1, 66.2, 62.2, 32.1, 25.4(3), 21.1, 20.9(2), 20.8, 20.7, 20.6, 17.7, $-4.8,-5.1 \mathrm{ppm}$; HRMS (ESI) $\mathrm{m} / z$ calcd for $\mathrm{C}_{33} \mathrm{H}_{52} \mathrm{O}_{16} \mathrm{SSiNa}$

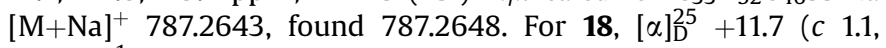
$\left.\mathrm{CHCl}_{3}\right) ;{ }^{1} \mathrm{H}$ NMR $\left(400 \mathrm{MHz}, \mathrm{CDCl}_{3}\right): \delta 5.91-5.87\left(\mathrm{~m}, 1 \mathrm{H}, \mathrm{CH}_{2} \mathrm{CH}=\right.$ $\mathrm{CH}_{2}$ ), 5.52 (d, $\left.J=3.2 \mathrm{~Hz}, 1 \mathrm{H}, \mathrm{H}-2^{\prime}\right), 5.31$ (dd, $J=17.2,1.2 \mathrm{~Hz}, 1 \mathrm{H}$, $\mathrm{CH}_{2} \mathrm{CH}=\mathrm{CH}_{2}$ ), 5.27-5.22 (m, 2H, H-4', $\left.\mathrm{CH}_{2} \mathrm{CH}=\mathrm{CH}_{2}\right), 5.11$ (dd, $J=3.6,1.6 \mathrm{~Hz}, 1 \mathrm{H}, \mathrm{H}-2), 5.07-5.01\left(\mathrm{~m}, 2 \mathrm{H}, \mathrm{H}-3^{\prime}, \mathrm{H}-4\right), 4.95(\mathrm{~s}, 1 \mathrm{H}, \mathrm{H}-$ $\left.1^{\prime}\right), 4.78(\mathrm{~s}, 1 \mathrm{H}, \mathrm{H}-1), 4.31-4.22\left(\mathrm{~m}, 2 \mathrm{H}, \mathrm{CH}_{2} \mathrm{CH}=\mathrm{CH}_{2}, \mathrm{H}-6 \mathrm{a}^{\prime}\right)$, 4.15-4.11 (m, 1H, H-6b' ) 4.07 (dd, $J=9.2,3.6 \mathrm{~Hz}, 1 \mathrm{H}, \mathrm{H}-3$ ), 4.00 (dd, $\left.J=13.2,6.0 \mathrm{~Hz}, 1 \mathrm{H}, \mathrm{CH}_{2} \mathrm{CH}=\mathrm{CH}_{2}\right), 3.79(\mathrm{dt}, J=9.6,2.4 \mathrm{~Hz}, 1 \mathrm{H}, \mathrm{H}-5)$, 3.72-3.67 (m, 1H, H-5'), 2.87 (dd, $J=14.0,9.6 \mathrm{~Hz}, 1 \mathrm{H}, \mathrm{H}-6 \mathrm{a}), 2.77$ (dd,
$J=14.0,2.4 \mathrm{~Hz}, 1 \mathrm{H}, \mathrm{H}-6 \mathrm{~b}), 2.17$ (s, 3H, OAc), 2.13 (s, 3H, OAc), 2.10 (s, $3 \mathrm{H}, \mathrm{OAc}), 2.07$ (s, 3H, OAc), 2.04 (s, 3H, OAc), 1.97 (s, 3H, OAc), 0.81 (s, $\left.9 \mathrm{H}, \mathrm{C}\left(\mathrm{CH}_{3}\right)_{3}\right), 0.06\left(\mathrm{~s}, 3 \mathrm{H}, \mathrm{Si}\left(\mathrm{CH}_{3}\right)_{2}\right), 0.04\left(\mathrm{~s}, 3 \mathrm{H}, \mathrm{Si}\left(\mathrm{CH}_{3}\right)_{2}\right) \mathrm{ppm}$; ${ }^{13} \mathrm{C}$ NMR $\left(100 \mathrm{MHz}, \mathrm{CDCl}_{3}\right): \delta 170.7,170.2,170.1(2), 170.0,169.6$, 133.3, 118.0, 96.6, 83.4, 76.5, 73.2, 72.4, 71.9, 71.8, 71.4, 70.4, 68.4, $68.1,65.7,62.8,32.9,25.4(3), 21.1,21.0,20.8,20.7,20.6,17.7$, $4.8,-5.1 \mathrm{ppm}$; HRMS (ESI) $\mathrm{m} / z$ calcd for $\mathrm{C}_{33} \mathrm{H}_{52} \mathrm{O}_{16} \mathrm{SSiNa}[\mathrm{M}+\mathrm{Na}]^{+}$ 787.2643, found 787.2650.

\subsection{Allyl 2,4-di-O-acetyl-6-S-(2,3,4,6-tetra-O-acetyl-a-D- mannopyranosyl)- $\alpha$-D-mannopyranoside (17)}

To a stirred solution of $\mathbf{1 6}(637 \mathrm{mg}, 0.83 \mathrm{mmol})$ in anhydrous $\mathrm{CH}_{2} \mathrm{Cl}_{2}(10 \mathrm{~mL})$ was added $\mathrm{HF}$-pyridine $(1.25 \mathrm{~mL})$ at $0{ }^{\circ} \mathrm{C}$. The mixture was stirred at room temperature for $1 \mathrm{~h}$ and the reaction was monitored by TLC (Petroleum ether/EtOAc $=1: 1$ ). When the starting material had disappeared, saturated aqueous sodium hydrogencarbonate was added carefully. The aqueous layer was extracted with $\mathrm{CH}_{2} \mathrm{Cl}_{2}(4 \times 15 \mathrm{~mL})$. The combined organic phase was dried over $\mathrm{Na}_{2} \mathrm{SO}_{4}$ and concentrated to a residue, which was subjected to silica gel column chromatography (petroleum ether/ EtOAc $=1.5 / 1)$ to afford $17(448 \mathrm{mg}, 83 \%)$ as a colorless syrup. $[\alpha]_{\mathrm{D}}^{25}+63.3\left(\right.$ c 1.0, $\left.\mathrm{CHCl}_{3}\right) ;{ }^{1} \mathrm{H} \mathrm{NMR}\left(400 \mathrm{MHz}, \mathrm{CDCl}_{3}\right): \delta$ 5.91-5.87 $\left(\mathrm{m}, 1 \mathrm{H}, \mathrm{CH}_{2} \mathrm{CH}=\mathrm{CH}_{2}\right), 5.33-5.31\left(\mathrm{~m}, 3 \mathrm{H}, \mathrm{H}-1^{\prime}, \mathrm{H}-2^{\prime}, \mathrm{H}-4^{\prime}\right)$, 5.29-5.24 (m, 2H, H-3', $\left.\mathrm{CH}_{2} \mathrm{CH}=\mathrm{CH}_{2}\right), 5.22(\mathrm{~d}, J=10.4 \mathrm{~Hz}, 1 \mathrm{H}$, $\left.\mathrm{CH}_{2} \mathrm{CH}=\mathrm{CH}_{2}\right), 5.08-5.03(\mathrm{~m}, 2 \mathrm{H}, \mathrm{H}-2, \mathrm{H}-4), 4.86(\mathrm{~s}, 1 \mathrm{H}, \mathrm{H}-1)$, $4.37-4.28\left(\mathrm{~m}, 2 \mathrm{H}, \mathrm{H}_{-} 5^{\prime}, \mathrm{H}_{-} 6 \mathrm{a}^{\prime}\right), 4.19\left(\mathrm{dd}, J=13.2,5.2 \mathrm{~Hz}, 1 \mathrm{H}, \mathrm{CH}_{2} \mathrm{CH}=\right.$ $\mathrm{CH}_{2}$ ), 4.10-4.05 (m, 2H, H-3, H-6b'), 4.00 (dd, J=13.2, $5.6 \mathrm{~Hz}, 1 \mathrm{H}$, $\mathrm{CH}_{2} \mathrm{CH}=\mathrm{CH}_{2}$ ), $3.91(\mathrm{dt}, J=10.0,2.4 \mathrm{~Hz}, 1 \mathrm{H}, \mathrm{H}-5), 2.84$ (dd, $J=13.6$, $2.4 \mathrm{~Hz}, 1 \mathrm{H}, \mathrm{H}-6 \mathrm{a}$ ), 2.69 (dd, $J=13.6,7.2 \mathrm{~Hz}, 1 \mathrm{H}, \mathrm{H}-6 \mathrm{~b}), 2.20$ (br, $1 \mathrm{H}$, $\mathrm{OH}), 2.15$ (s, 6H, OAc), 2.12 (s, 3H, OAc), 2.10 (s, 3H, OAc), 2.04 (s, 3H, $\mathrm{OAc}), 1.98(\mathrm{~s}, 3 \mathrm{H}, \mathrm{OAc}) \mathrm{ppm} ;{ }^{13} \mathrm{C} \mathrm{NMR}\left(100 \mathrm{MHz}, \mathrm{CDCl}_{3}\right): \delta 171.2$, 170.6(2), 169.9, 169.8, 169.7, 133.1, 118.0, 96.2, 82.5, 72.4, 72.0, 70.8, 69.3, 69.2, 69.1, 68.4, 68.3, 66.1, 62.2, 31.9, 21.0, 20.9(2), 20.8, 20.7, 20.6 ppm; HRMS (ESI) $\mathrm{m} / \mathrm{z}$ calcd for $\mathrm{C}_{27} \mathrm{H}_{38} \mathrm{O}_{16} \mathrm{SNa}[\mathrm{M}+\mathrm{Na}]^{+}$ 673.1778 , found 673.1798 .

\subsection{Allyl 2,4-di-O-acetyl-3-0-(2,3,4-tri-O-benzoyl-6-O-t- butyldimethylsilyl- $\alpha$-D-mannopyranosyl) -6-S-(2,3,4,6-tetra-O- acetyl-a-D-mannopyranosyl)- $\alpha$-D-mannopyranoside (20)}

A mixture of 17 (334 mg, $0.51 \mathrm{mmol})$ and freshly dried $4 \AA$ molecular sieves $(400 \mathrm{mg})$ in anhydrous dichloromethane $(4 \mathrm{~mL})$ was stirred for $10 \mathrm{~min}$ under nitrogen at $-78^{\circ} \mathrm{C}$, and TMSOTf $(14 \mu \mathrm{L}$, $0.08 \mathrm{mmol}$ ) was added quickly. Then a solution of compound 19 (824 mg, $1.1 \mathrm{mmol}$ ) in dry $\mathrm{CH}_{2} \mathrm{Cl}_{2}(3 \mathrm{~mL})$ was added dropwise. The reaction was stirred at $-78{ }^{\circ} \mathrm{C}$ until TLC indicated complete conversion of the accepter 17 and then quenched with $\mathrm{Et}_{3} \mathrm{~N}$ ( 5 drops). Solid was filtered and washed with dichloromethane. The filtrate was concentrated in vacuo to obtain an oily residue that was purified by silica gel column chromatography (petroleum ether/ $\mathrm{EtOAc}=3 / 1)$ to furnish $20(420 \mathrm{mg}, 66 \%)$ as a colorless syrup. $[\alpha]_{\mathrm{D}}^{25}+4.4\left(\right.$ c 2.2, $\left.\mathrm{CHCl}_{3}\right) ;{ }^{1} \mathrm{H}$ NMR $\left(400 \mathrm{MHz}, \mathrm{CDCl}_{3}\right): \delta 8.09$ (dd, $J=8.4,1.2 \mathrm{~Hz}, 2 \mathrm{H}), 7.97(\mathrm{dd}, J=8.4,1.6 \mathrm{~Hz}, 2 \mathrm{H}), 7.85(\mathrm{dd}, J=8.4,1.2 \mathrm{~Hz}$, $2 \mathrm{H}), 7.59$ (tt, $J=7.2,1.2 \mathrm{~Hz}, 1 \mathrm{H}), 7.53-7.43(\mathrm{~m}, 3 \mathrm{H}), 7.41-7.36(\mathrm{~m}, 3 \mathrm{H})$, $7.28-7.24(\mathrm{~m}, 2 \mathrm{H}), 6.03\left(\mathrm{t}, J=10.0 \mathrm{~Hz}, 1 \mathrm{H}, \mathrm{H}-4^{\prime}\right), 5.92-5.88(\mathrm{~m}, 1 \mathrm{H}$, $\mathrm{CH}_{2} \mathrm{CH}=\mathrm{CH}_{2}$ ), $5.67\left(\mathrm{dd}, J=10.0,3.6 \mathrm{~Hz}, 1 \mathrm{H}, \mathrm{H}-3^{\prime}\right), 5.42(\mathrm{dd}, J=3.2$, $\left.1.6 \mathrm{~Hz}, 1 \mathrm{H}, \mathrm{H}-2^{\prime}\right), 5.37-5.35\left(\mathrm{~m}, 3 \mathrm{H}, \mathrm{H}-2, \mathrm{H}-2^{\prime \prime}, \mathrm{CH}_{2} \mathrm{CH}=\mathrm{CH}_{2}\right), 5.33$ (s, $\left.1 \mathrm{H}, \mathrm{H}-1^{\prime \prime}\right), 5.31-5.30$ (m, 3H, H-3", H-4, H-4" $\left.{ }^{\prime \prime}\right), 5.27$ (d, J=1.6 Hz, $1 \mathrm{H}, \mathrm{H}_{-1}^{\prime}$ ), 5.24 (dd, $\left.J=10.4,1.2 \mathrm{~Hz}, 1 \mathrm{H}, \mathrm{CH}_{2} \mathrm{CH}=\mathrm{CH}_{2}\right), 4.86$ (d, $J=1.6 \mathrm{~Hz}, 1 \mathrm{H}, \mathrm{H}-1), 4.43-4.39\left(\mathrm{~m}, 1 \mathrm{H}, \mathrm{H}-5^{\prime \prime}\right), 4.35-4.29$ (m, 2H, H-3, $\left.\mathrm{H}-6 \mathrm{a}^{\prime \prime}\right), 4.25-4.18\left(\mathrm{~m}, 2 \mathrm{H}, \mathrm{H}-5^{\prime}, \mathrm{CH}_{2} \mathrm{CH}=\mathrm{CH}_{2}\right), 4.13-4.08(\mathrm{~m}, 1 \mathrm{H}, \mathrm{H}-$ $\left.6 b^{\prime \prime}\right), 4.04\left(\mathrm{dd}, J=12.8,6.0 \mathrm{~Hz}, 1 \mathrm{H}, \mathrm{CH}_{2} \mathrm{CH}=\mathrm{CH}_{2}\right), 3.93-3.87(\mathrm{~m}, 1 \mathrm{H}$, $\mathrm{H}-5$ ), 3.85-3.78 (m, 2H, H-6a', 6b'), 2.85-2.75 (m, 2H, H-6a,b), 2.30 (s, 3H, OAc), 2.23 (s, 3H, OAc), 2.17 (s, 3H, OAc), 2.14 (s, 3H, OAc), 
2.06 (s, 3H, OAc), 1.99 (s, 3H, OAc), 0.88 (s, 9H, C( $\left.\left.\mathrm{CH}_{3}\right)_{3}\right), 0.01$ (s, 3H, $\left.\mathrm{Si}\left(\mathrm{CH}_{3}\right)_{2}\right),-0.02\left(\mathrm{~s}, 3 \mathrm{H}, \mathrm{Si}\left(\mathrm{CH}_{3}\right)_{2}\right) \mathrm{ppm} ;{ }^{13} \mathrm{C} \mathrm{NMR}\left(100 \mathrm{MHz}, \mathrm{CDCl}_{3}\right)$ : $\delta$ 170.7, 170.5, 170.4, 169.9, 169.7(2), 165.6, 165.4, 165.3, 133.5, 133.2, 133.0, 129.9(2), 129.8(2), 129.7(2), 129.5, 129.3, 129.2, 128.5(2), 128.4(2), 128.3(2), 118.4, 98.9, 96.3, 82.4, 74.4, 72.1, 71.0, 70.9, 70.8(2), 70.7, 69.9, 69.8, 69.4, 69.1, 68.3, 66.3, 66.2, 62.3, 61.8, 32.1, 25.9(3), 21.1, 21.0, 20.9, 20.8, 20.7, 20.6, 18.3, -5.5, -5.6 ppm; MALDI-TOF MS $m / z$ calcd for $\mathrm{C}_{60} \mathrm{H}_{74} \mathrm{O}_{24} \mathrm{SSiNa}[\mathrm{M}+\mathrm{Na}]^{+} 1261.4$, found 1261.3 .

\subsection{Allyl 2,4-di-O-acetyl-3-O-(2,3,4-tri-O-benzoyl- $\alpha$-D- mannopyranosyl)-6-S-(2,3,4,6-tetra-O-acetyl- $\alpha-D-$ mannopyranosyl)- $\alpha$-D-mannopyranoside (21)}

To a stirred solution of $\mathbf{2 0}$ (140 $\mathrm{mg}, 0.11 \mathrm{mmol}$ ) in anhydrous $\mathrm{CH}_{2} \mathrm{Cl}_{2}(2 \mathrm{~mL})$ and pyridine $(0.5 \mathrm{~mL})$ was added HF-pyridine $(1.0 \mathrm{~mL})$ at $0{ }^{\circ} \mathrm{C}$. The mixture was stirred at room temperature for $8 \mathrm{~h}$ and the reaction process was monitored by TLC (Petroleum ether/EtOAc=1:1). When the starting material had disappeared, saturated aqueous sodium bicarbonate was added carefully. The aqueous layer was extracted with $\mathrm{CH}_{2} \mathrm{Cl}_{2}(4 \times 15 \mathrm{~mL})$. The combined organic phase was dried and concentrated to a syrup that was purified by silica gel column chromatography (petroleum ether/ EtOAc $=2 / 1)$ to give $21(122 \mathrm{mg}, 87 \%)$ as a colorless syrup. $[\alpha]_{\mathrm{D}}^{25}+3.4$ (c 1.0, $\left.\mathrm{CHCl}_{3}\right) ;{ }^{1} \mathrm{H} \mathrm{NMR}\left(400 \mathrm{MHz}, \mathrm{CDCl}_{3}\right): \delta 8.07(\mathrm{~d}, J=7.2 \mathrm{~Hz}, 2 \mathrm{H})$, 7.99 (d, $J=7.8 \mathrm{~Hz}, 2 \mathrm{H}), 7.82(\mathrm{~d}, J=7.2 \mathrm{~Hz}, 2 \mathrm{H}), 7.60(\mathrm{t}, J=7.2 \mathrm{~Hz}, 1 \mathrm{H})$, $7.54-7.45(\mathrm{~m}, 3 \mathrm{H}), 7.43-7.37(\mathrm{~m}, 3 \mathrm{H}), 7.25(\mathrm{t}, J=7.8 \mathrm{~Hz}, 2 \mathrm{H})$, 5.93-5.78 (m, 3H, $\left.\mathrm{CH}_{2} \mathrm{CH}=\mathrm{CH}_{2}, \mathrm{H}-3^{\prime}, \mathrm{H}^{-} 4^{\prime}\right), 5.45(\mathrm{t}, J=2.0 \mathrm{~Hz}, 1 \mathrm{H}, \mathrm{H}-$ $2^{\prime}$ ), 5.37-5.27 ( $\mathrm{m}, 8 \mathrm{H}, \mathrm{H}-2, \mathrm{H}-4, \mathrm{H}-1^{\prime}, \mathrm{H}-1^{\prime \prime}, \mathrm{H}-2^{\prime \prime}, \mathrm{H}-3^{\prime \prime}, \mathrm{H}-4^{\prime \prime}$, $\left.\mathrm{CH}_{2} \mathrm{CH}=\mathrm{CH}_{2}\right), 5.22\left(\mathrm{~d}, J=10.4 \mathrm{~Hz}, 1 \mathrm{H}, \mathrm{CH}_{2} \mathrm{CH}=\mathrm{CH}_{2}\right), 4.84(\mathrm{~s}, 1 \mathrm{H}, \mathrm{H}-$ 1), 4.41-4.38 (m, $\left.1 \mathrm{H}, \mathrm{H}-5^{\prime \prime}\right), 4.34-4.27\left(\mathrm{~m}, 2 \mathrm{H}, \mathrm{H}-3, \mathrm{H}-6 \mathrm{a}^{\prime \prime}\right), 4.22(\mathrm{dd}$, $\left.J=12.8,5.2 \mathrm{~Hz}, 1 \mathrm{H}, \mathrm{CH}_{2} \mathrm{CH}=\mathrm{CH}_{2}\right), 4.14-4.08\left(\mathrm{~m}, 2 \mathrm{H}, \mathrm{H}-5^{\prime}, \mathrm{H}-6 \mathrm{~b}^{\prime \prime}\right)$, 4.02 (dd, $J=12.8,6.0 \mathrm{~Hz}, 1 \mathrm{H}, \mathrm{CH}_{2} \mathrm{CH}=\mathrm{CH}_{2}$ ), 3.91 (dt, $J=7.2,2.8 \mathrm{~Hz}$, $1 \mathrm{H}, \mathrm{H}-5), 3.83-3.78\left(\mathrm{~m}, 1 \mathrm{H}, \mathrm{H}-6 \mathrm{a}^{\prime}\right), 3.74-3.70\left(\mathrm{~m}, 1 \mathrm{H}, \mathrm{H}-6 \mathrm{~b}^{\prime}\right), 2.84$ (dd, $J=14.0,2.8 \mathrm{~Hz}, 1 \mathrm{H}, \mathrm{H}-6 \mathrm{a}$ ), 2.76 (dd, $J=14.0,7.6 \mathrm{~Hz}, 1 \mathrm{H}, \mathrm{H}-6 \mathrm{~b}$ ), $2.59(\mathrm{t}, J=6.0 \mathrm{~Hz}, 1 \mathrm{H}, \mathrm{OH}), 2.27(\mathrm{~s}, 3 \mathrm{H}, \mathrm{OAc}), 2.24(\mathrm{~s}, 3 \mathrm{H}, \mathrm{OAc}), 2.16(\mathrm{~s}$, 3H, OAc), 2.13 (s, 3H, OAc), 2.05 (s, 3H, OAc), 1.99 (s, 3H, OAc) ppm; ${ }^{13} \mathrm{C}$ NMR $\left(100 \mathrm{MHz}, \mathrm{CDCl}_{3}\right): \delta 170.7(2), 170.4,169.9,169.7(2), 166.5$, 165.6, 165.2, 133.7, 133.2, 132.9, 130.0(2), 129.9(2), 129.7(2), 129.1(2), 128.7, 128.6(2), 128.5(2), 128.3(2), 118.3, 99.2, 96.4, 82.4, 75.1, 71.8, 70.9, 70.8(3), 70.3, 69.8, 69.4, 69.2, 69.0, 68.4, 66.9, 66.2, 62.3, 61.2, 32.0, 21.1, 20.9, 20.8, 20.7(2), 20.6 ppm; MALDI-TOF MS $m / z$ calcd for $\mathrm{C}_{54} \mathrm{H}_{60} \mathrm{O}_{24} \mathrm{SNa}[\mathrm{M}+\mathrm{Na}]^{+}$1147.3, found 1147.3.

4.11. Allyl $\alpha$-D-mannopyranosyl-( $1 \rightarrow 3)$-[6-S- $\alpha$-D-mannopyranosyl$(1 \rightarrow 6)]-\alpha$-D-mannopyranose $(\mathbf{1})$

To a solution of 21 (122 mg, $0.11 \mathrm{mmol})$ in anhydrous methanol $(10 \mathrm{~mL})$ under nitrogen was added a $1 \mathrm{M}$ solution of sodium methoxide in $\mathrm{MeOH}$ until $\mathrm{pH}$ 9-10 was reached. The reaction mixture was stirred at $\mathrm{rt}$ for $10 \mathrm{~h}$. Upon completion (TLC), the reaction was neutralized with amberlite IR-120 $\left(\mathrm{H}^{+}\right)$and filtered, solvent was evaporated to dryness. The residue was purified with Sephadex G-10 and desired fractions were combined and lyophilized to furnish compound $1(58.3 \mathrm{mg}, 96 \%)$ as white foam. $[\alpha]_{\mathrm{D}}^{25}+91.6\left(\right.$ c $\left.0.68, \mathrm{H}_{2} \mathrm{O}\right) ;{ }^{1} \mathrm{H} \mathrm{NMR}\left(400 \mathrm{MHz}, \mathrm{CDCl}_{3}\right): \delta 5.92-5.87$ $\left(\mathrm{m}, 1 \mathrm{H}, \mathrm{CH}_{2} \mathrm{CH}=\mathrm{CH}_{2}\right), 5.34-5.28\left(\mathrm{~m}, 2 \mathrm{H}, \mathrm{H}-1^{\prime \prime}, \mathrm{CH}_{2} \mathrm{CH}=\mathrm{CH}_{2}\right), 5.18$ (dd, $\left.J=10.4,1.2 \mathrm{~Hz}, 1 \mathrm{H}, \mathrm{CH}_{2} \mathrm{CH}=\mathrm{CH}_{2}\right), 5.06\left(\mathrm{~d}, J=1.6 \mathrm{~Hz}, 1 \mathrm{H}, \mathrm{H}-1^{\prime}\right.$ ), $4.74(\mathrm{~d}, J=1.6 \mathrm{~Hz}, 1 \mathrm{H}, \mathrm{H}-1), 4.23$ (ddt, $2 \mathrm{H}, J=13.2,5.2,1.2 \mathrm{~Hz}$, $\left.\mathrm{CH}_{2} \mathrm{CH}=\mathrm{CH}_{2}\right), 4.05-3.99\left(\mathrm{~m}, 2 \mathrm{H}, \mathrm{H}-2, \mathrm{CH}_{2} \mathrm{CH}=\mathrm{CH}_{2}\right), 3.96(\mathrm{dd}$, $\left.J=3.2,1.6 \mathrm{~Hz}, 1 \mathrm{H}, \mathrm{H}-2^{\prime}\right), 3.94-3.65\left(\mathrm{~m}, 13 \mathrm{H}, \mathrm{H}-3, \mathrm{H}-5, \mathrm{H}-3^{\prime}, \mathrm{H}-4^{\prime}, \mathrm{H}-\right.$ $\left.5^{\prime}, \mathrm{H}-6 \mathrm{a}^{\prime}, \mathrm{H}-6 \mathrm{~b}^{\prime}, \mathrm{H}-2^{\prime \prime}, \mathrm{H}-3^{\prime \prime}, \mathrm{H}-4^{\prime \prime}, \mathrm{H}-5^{\prime \prime}, \mathrm{H}-6 \mathrm{a}^{\prime \prime}, \mathrm{H}-6 \mathrm{~b}^{\prime \prime}\right), 3.61$ (t, $J=9.6 \mathrm{~Hz}, 1 \mathrm{H}, \mathrm{H}-4), 3.15$ (dd, $J=14.0,2.0 \mathrm{~Hz}, 1 \mathrm{H}, \mathrm{H}-6 \mathrm{a}$ ), 2.75 (dd, $J=14.0,3.6 \mathrm{~Hz}, 1 \mathrm{H}, \mathrm{H}-6 \mathrm{~b}) \mathrm{ppm} ;{ }^{13} \mathrm{C} \mathrm{NMR}\left(100 \mathrm{MHz}, \mathrm{CDCl}_{3}\right): \delta 137.9$, 120.2, 106.5, 103.3, 89.0, 82.9, 77.6, 77.5, 76.3, 76.2, 75.7, 75.0, 74.6,
74.0, 72.7, 71.5, 71.4, 71.3, 65.4, 65.3, 35.7 ppm; HRMS (ESI) $\mathrm{m} / \mathrm{z}$ calcd for $\mathrm{C}_{21} \mathrm{H}_{36} \mathrm{O}_{15} \mathrm{SNa}[\mathrm{M}-\mathrm{H}]^{-}$559.1697, found 559.1715.

4.12. 3-((2-t-Butoxycarbonylamino)ethylthio)propyl 2,4-di-Oacetyl-3-0-(2,3,4-tri-O-benzoyl-6-O-t-butyldimethylsilyl- $\alpha-D-$ mannopyranosyl)-6-S-(2,3,4,6-tetra-O-acetyl- $\alpha$-Dmannopyranosyl)- $\alpha$-D-mannopyranoside (22)

A solution of 20 (208 $\mathrm{mg}, 0.16 \mathrm{mmol}), 2-t$-butylcarbamateethanethiol 3 (170 mg, $0.96 \mathrm{mmol}$ ) and AIBN (13.8 mg, $0.08 \mathrm{mmol}$ ) in toluene $(10 \mathrm{~mL})$ was degassed with $\mathrm{N}_{2}$ and refluxed for $4 \mathrm{~h}$. The solution was cooled and the solvent removed in vacuo. The remaining oily residue was then purified by silica gel column chromatography (petroleum ether/EtOAc $=2 / 1)$ to give $\mathbf{2 2}(211 \mathrm{mg}$, $89 \%)$ as a colorless syrup. $[\alpha]_{D}^{25}+6.7$ (c 2.7, $\left.\mathrm{CHCl}_{3}\right) ;{ }^{1} \mathrm{H}$ NMR (400 MHz, $\mathrm{CDCl}_{3}$ ): $\delta 8.08$ (dd, $J=6.8,1.2 \mathrm{~Hz}, 2 \mathrm{H}$ ), 7.95 (dd, $J=7.2$, $1.6 \mathrm{~Hz}, 2 \mathrm{H}), 7.83$ (dd, $J=7.2,1.2 \mathrm{~Hz}, 2 \mathrm{H}), 7.58(\mathrm{t}, J=7.2 \mathrm{~Hz}, 1 \mathrm{H}$ ), $7.51-7.41(\mathrm{~m}, 3 \mathrm{H}), 7.39-7.35(\mathrm{~m}, 3 \mathrm{H}), 7.24(\mathrm{t}, J=6.8 \mathrm{~Hz}, 2 \mathrm{H}), 6.03(\mathrm{t}$, $\left.J=10.0 \mathrm{~Hz}, 1 \mathrm{H}, \mathrm{H}-4^{\prime}\right), 5.66$ (dd, $\left.J=10.4,3.2 \mathrm{~Hz}, 1 \mathrm{H}, \mathrm{H}-3^{\prime}\right), 5.42$ (dd, $J=3.2,1.6 \mathrm{~Hz}, 1 \mathrm{H}, \mathrm{H}-2^{\prime}$ ), 5.35 (dd, $J=2.8,1.2 \mathrm{~Hz}, 1 \mathrm{H}, \mathrm{H}-2$ ), $5.34-5.27$ ( $\left.\mathrm{m}, 5 \mathrm{H}, \mathrm{H}-1^{\prime}, \mathrm{H}-1^{\prime \prime}, \mathrm{H}-3^{\prime \prime}, \mathrm{H}-4, \mathrm{H}-4^{\prime \prime}\right), 5.26$ (d, $J=1.6 \mathrm{~Hz}, 1 \mathrm{H}, \mathrm{H}-2^{\prime \prime}$ ), 5.05 (br, $1 \mathrm{H}, \mathrm{NH}), 4.79$ (d, J=1.2 Hz, 1H, H-1), 4.42-4.38 (m, 1H, H$5^{\prime \prime}$ ), 4.31 (dd, $\left.J=12.4,5.2 \mathrm{~Hz}, 1 \mathrm{H}, \mathrm{H}-6 \mathrm{a}^{\prime \prime}\right), 4.23$ (dd, $J=9.6,3.2 \mathrm{~Hz}, 1 \mathrm{H}$, $\mathrm{H}-3$ ) 4.18 (dt, $\left.J=10.0,2.4 \mathrm{~Hz}, 1 \mathrm{H}, \mathrm{H}-5^{\prime}\right), 4.11-4.07$ (dd, $J=12.4,6.0 \mathrm{~Hz}$, $\left.1 \mathrm{H}, \mathrm{H}-6 \mathrm{~b}^{\prime \prime}\right), 3.90-3.83\left(\mathrm{~m}, 2 \mathrm{H}, \mathrm{H}-5, \mathrm{OCH}_{2} \mathrm{CH}_{2}\right), 3.80-3.76(\mathrm{~m}, 2 \mathrm{H}, \mathrm{H}-$ $\left.6 \mathrm{a}^{\prime}, 6 \mathrm{~b}^{\prime}\right), 3.51\left(\mathrm{dt}, J=10.0,6.0 \mathrm{~Hz}, 1 \mathrm{H}, \mathrm{OCH}_{2} \mathrm{CH}_{2}\right), 3.30(\mathrm{~d}, J=6.0 \mathrm{~Hz}$, $2 \mathrm{H}, \mathrm{CH}_{2} \mathrm{NH}$ ), 2.82 (dd, $J=14.0,2.8 \mathrm{~Hz}, 1 \mathrm{H}, \mathrm{H}-6 \mathrm{a}$ ), 2.75 (dd, $J=14.0$, $8.0 \mathrm{~Hz}, 1 \mathrm{H}, \mathrm{H}-6 \mathrm{~b}), 2.65-2.58$ ( $\mathrm{m}, 4 \mathrm{H}, \mathrm{CH}_{2} \mathrm{SCH}_{2}$ ), 2.28 (s, 3H, OAc), 2.23 (s, 3H, OAc), 2.16 (s, 3H, OAc), 2.13 (s, 3H, OAc), 2.04 (s, 3H, $\mathrm{OAc}), 1.98$ (s, 3H, OAc), 1.93-1.84 (m, 2H, $\left.\mathrm{CH}_{2} \mathrm{CH}_{2} \mathrm{CH}_{2}\right), 1.41(\mathrm{~s}, 9 \mathrm{H}$, $\left.\mathrm{NH}\left(\mathrm{CH}_{3}\right)_{3}\right), 0.87\left(\mathrm{~s}, 9 \mathrm{H}, \mathrm{C}\left(\mathrm{CH}_{3}\right)_{3}\right),-0.01\left(\mathrm{~s}, 3 \mathrm{H}, \mathrm{Si}\left(\mathrm{CH}_{3}\right)_{2}\right),-0.04(\mathrm{~s}$, $\left.3 \mathrm{H}, \mathrm{Si}\left(\mathrm{CH}_{3}\right)_{2}\right) \mathrm{ppm} ;{ }^{13} \mathrm{C} \mathrm{NMR}\left(100 \mathrm{MHz}, \mathrm{CDCl}_{3}\right): \delta 170.7,170.5,170.4$, 169.9, 169.8, 169.7, 165.6, 165.3, 165.2, 155.8, 133.5, 133.2, 133.0, 129.9(2), 129.7(2), 129.6(2), 129.5, 129.2(2), 128.5(2), 128.4(2), 128.3(2), 99.0, 97.4, 82.3, 79.3, 74.8, 72.1, 70.9, 70.8(3), 70.5, 69.9, $69.8,69.5,69.1,66.5,66.2,62.3,61.7,39.7,32.1,32.0,29.0,28.4(3)$, 28.2, 25.9(3), 21.1, 20.9, 20.8, 20.7(2), 20.6, 18.3, -5.5, -5.7 ppm; MALDI-TOF MS $m / z$ calcd for $\mathrm{C}_{67} \mathrm{H}_{89} \mathrm{NO}_{26} \mathrm{~S}_{2} \mathrm{SiNa}[\mathrm{M}+\mathrm{Na}]^{+}$1438.5, found 1438.5 .

4.13. 3-((2-t-Butoxycarbonylamino)ethylthio)propyl 2,4-di-Oacetyl-3-O-(2,3,4-tri-O-benzoyl-6-O-acet yl- $\alpha$-D-mannopyranosyl)$6-S-(2,3,4,6$-tetra-O-acetyl- $\alpha$-D-mannopyranosyl)- $\alpha-D-$ mannopyranosid (24)

To a stirred solution of $22(200 \mathrm{mg}, 0.14 \mathrm{mmol})$ in anhydrous $\mathrm{CH}_{2} \mathrm{Cl}_{2}(2 \mathrm{~mL})$ and pyridine $(0.5 \mathrm{~mL})$ was added HF-pyridine $(0.5 \mathrm{~mL})$ at $0{ }^{\circ} \mathrm{C}$. The mixture was stirred at rt for $8 \mathrm{~h}$ and monitored by TLC (Petroleum ether/EtOAc $=1: 1$ ). When the starting material had disappeared, saturated aqueous sodium bicarbonate was added carefully. The aqueous layer was extracted with $\mathrm{CH}_{2} \mathrm{Cl}_{2}$ $(4 \times 15 \mathrm{~mL})$. The combined organic phase was dried and then concentrated to afford a syrup. To a solution of the syrup in pyridine $(10 \mathrm{~mL})$ was added $\mathrm{Ac}_{2} \mathrm{O}(0.03 \mathrm{~mL}, 0.28 \mathrm{mmol})$. The reaction mixture was stirred at $\mathrm{rt}$ for $4 \mathrm{~h}$ and then evaporated under vacuo to give a yellow oil. Purification by silica gel column chromatography (petroleum ether/EtOAc $=1.5 / 1)$ give $\mathbf{2 4}(139 \mathrm{mg}, 74 \%)$ as a colorless syrup. $[\alpha]_{\mathrm{D}}^{25}+8.9\left(\right.$ c $\left.2.5, \mathrm{CHCl}_{3}\right) ;{ }^{1} \mathrm{H}$ NMR $\left(400 \mathrm{MHz}, \mathrm{CDCl}_{3}\right): \delta 8.06$ $(\mathrm{d}, J=7.2 \mathrm{~Hz}, 2 \mathrm{H}), 7.96$ (d, J=7.2 Hz, 2H), 7.81 (d, J=7.2 Hz, 2H), 7.59(t, $J=7.2 \mathrm{~Hz}, 1 \mathrm{H}), 7.51-7.44(\mathrm{~m}, 3 \mathrm{H}), 7.41-7.34(\mathrm{~m}, 3 \mathrm{H}), 7.24(\mathrm{t}, J=7.6 \mathrm{~Hz}$, $2 \mathrm{H}), 5.91\left(\mathrm{t}, J=10.0 \mathrm{~Hz}, 1 \mathrm{H}, \mathrm{H}-4^{\prime}\right), 5.70\left(\mathrm{dd}, J=10.0,2.8 \mathrm{~Hz}, 1 \mathrm{H}, \mathrm{H}-3^{\prime}\right)$, $5.42\left(\mathrm{dd}, J=2.8,2.0 \mathrm{~Hz}, 1 \mathrm{H}, \mathrm{H}-2^{\prime}\right), 5.35-5.26$ (m, 7H, H-1', H-2, H-4, $\left.\mathrm{H}-1^{\prime \prime}, \mathrm{H}-2^{\prime \prime}, \mathrm{H}-3^{\prime \prime}, \mathrm{H}-4^{\prime \prime}\right), 5.06$ (br, $\left.1 \mathrm{H}, \mathrm{NH}\right), 4.81$ (s, 1H, H-1), 4.39-4.37 (m, 2H, H-5', H-5") $4.34-4.28$ (m, 2H, H-6a', H-6a'), $4.25-4.21\left(\mathrm{~m}, 2 \mathrm{H}, \mathrm{H}-6 \mathrm{~b}^{\prime}, \mathrm{H}-3\right)$ 4.11-4.07 (m, 1H, H-6b' $\left.\mathrm{b}^{\prime \prime}\right), 3.89-3.82$ 
(m, $2 \mathrm{H}, \mathrm{H}-5, \mathrm{OCH}_{2} \mathrm{CH}_{2}$ ), 3.51 (dt, $J=9.6,6.0 \mathrm{~Hz}, 1 \mathrm{H}, \mathrm{OCH}_{2} \mathrm{CH}_{2}$ ), 3.28 (d, $J=5.6 \mathrm{~Hz}, 2 \mathrm{H}, \mathrm{CH}_{2} \mathrm{NH}$ ), 2.82 (dd, $J=14.0,2.4 \mathrm{~Hz}, 1 \mathrm{H}, \mathrm{H}-6 \mathrm{a}$ ), 2.75 (dd, $J=14.0,7.6 \mathrm{~Hz}, 1 \mathrm{H}, \mathrm{H}-6 \mathrm{~b}$ ), 2.63-2.57 (m, 4H, $\mathrm{CH}_{2} \mathrm{SCH}_{2}$ ), 2.28 (s, 3H, OAc), 2.23 (s, 3H, OAc), 2.15 (s, 3H, OAc), 2.12 (s, 3H, OAc), 2.06 (s, 3H, OAc), 2.04 (s, 3H, OAc), 1.97 (s, 3H, OAc), 1.91-1.83 (m, 2H, $\left.\mathrm{CH}_{2} \mathrm{CH}_{2} \mathrm{CH}_{2}\right), 1.40$ (s, 9H, $\left.\mathrm{NH}\left(\mathrm{CH}_{3}\right)_{3}\right) \mathrm{ppm} ;{ }^{13} \mathrm{C} \mathrm{NMR}(100 \mathrm{MHz}$, $\left.\mathrm{CDCl}_{3}\right): \delta 170.7,170.6,170.5,170.4,169.9,169.8,169.7,165.5,165.4$, 165.2, 155.8, 133.7, 133.5, 133.2, 129.9(2), 129.8(2), 129.7(2), 129.1, 129.0, 128.9, 128.6(2), 128.5(2), 128.3(2), 98.8, 97.3, 82.4, 79.3, 74.9, 70.8(2), 70.6, 70.4, 69.9, 69.5, 69.4, 69.2, 69.1, 66.6, 66.5, 66.2, 62.6, 62.3, 39.7, 32.1, 31.9, 29.0, 28.4(3), 28.2, 21.0, 20.9, 20.8, 20.7(2), 20.6(2) ppm; MALDI-TOF MS m/z calcd for $\mathrm{C}_{63} \mathrm{H}_{77} \mathrm{NO}_{27} \mathrm{~S}_{2} \mathrm{Na}$ $[\mathrm{M}+\mathrm{Na}]^{+} 1366.4$, found 1366.4 .

4.14. 3-(2-Aminoethylthio)propyl 2,4-di-O-acetyl-3-O-(2,3,4-tri-Obenzoyl-6-O-acetyl- $\alpha$-D-manno pyranosyl)-6-S-(2,3,4,6-tetra-Oacetyl- $\alpha$-D-mannopyranosyl)- $\alpha$-D-mannopyranoside (25)

To a solution of $24(139 \mathrm{mg}, 0.10 \mathrm{mmol})$ in $\mathrm{CH}_{2} \mathrm{Cl}_{2}(2 \mathrm{~mL})$ was added TFA $(0.06 \mathrm{~mL}, 0.54 \mathrm{mmol})$. The mixture was stirred at room temperature for $6 \mathrm{~h}$, and when the starting material had disappeared, The reaction mixture was then concentrated under reduced pressure to a residue that was purified by silica gel column chromatography (EtOAc/MeOH=10/1) to afford $25(102 \mathrm{mg}, 82 \%)$ as a colorless syrup. $[\alpha]_{\mathrm{D}}^{25}+11.8\left(\right.$ c $\left.1.0, \mathrm{CHCl}_{3}\right) ;{ }^{1} \mathrm{H}$ NMR $(400 \mathrm{MHz}$, $\left.\mathrm{CDCl}_{3}\right): \delta 8.15(\mathrm{br}, 2 \mathrm{H}, \mathrm{NH}), 8.08(\mathrm{~d}, J=8.0 \mathrm{~Hz}, 2 \mathrm{H}), 7.97(\mathrm{~d}, J=8.0 \mathrm{~Hz}$, $2 \mathrm{H}), 7.83(\mathrm{~d}, J=8.0 \mathrm{~Hz}, 2 \mathrm{H}), 7.61(\mathrm{t}, J=7.6 \mathrm{~Hz}, 1 \mathrm{H}), 7.53-7.46(\mathrm{~m}, 3 \mathrm{H})$, 7.44-7.37 (m, 3H), 7.26 (t, $J=6.8 \mathrm{~Hz}, 2 \mathrm{H}), 5.94(\mathrm{t}, J=10.0 \mathrm{~Hz}, 1 \mathrm{H}, \mathrm{H}-$ $4^{\prime}$ ), 5.70 (dd, $\left.J=10.0,3.2 \mathrm{~Hz}, 1 \mathrm{H}, \mathrm{H}-3^{\prime}\right), 5.43$ (s, 1H, H-2'), 5.36 (d, $\left.J=3.2 \mathrm{~Hz}, 1 \mathrm{H}, \mathrm{H}-2^{\prime \prime}\right), 5.34-5.27$ (m, 5H, H-1', H-2, H-4, H-1", H- $4^{\prime \prime}$ ), 5.21 (dd, $J=10.0,3.2 \mathrm{~Hz}, 1 \mathrm{H}, \mathrm{H}-3^{\prime \prime}$ ), 4.81 (s, 1H, H-1), 4.40-4.36 (m, 2H, H-5', H-5" ), 4.32-4.28 (m, 3H, H-6a', H-6a", H-6b'), 4.23 (dd, $J=10.0,3.2 \mathrm{~Hz}, 1 \mathrm{H}, \mathrm{H}-3), 4.11$ (d, $\left.J=11.6 \mathrm{~Hz}, 1 \mathrm{H}, \mathrm{H}-6 \mathrm{~b}^{\prime}\right), 3.90-3.83(\mathrm{~m}$, $2 \mathrm{H}, \mathrm{H}-5, \mathrm{OCH}_{2} \mathrm{CH}_{2}$ ), 3.54 (dt, J=9.6, $\left.6.0 \mathrm{~Hz}, 1 \mathrm{H}, \mathrm{OCH}_{2} \mathrm{CH}_{2}\right), 3.15$ (t, $\left.J=6.0 \mathrm{~Hz}, 2 \mathrm{H}, \mathrm{CH}_{2} \mathrm{NH}\right), 2.83-2.78\left(\mathrm{~m}, 4 \mathrm{H}, \mathrm{H}-6 \mathrm{a}, \mathrm{H}-6 \mathrm{~b}, \mathrm{SCH}_{2} \mathrm{CH}_{2} \mathrm{NH}_{2}\right)$, 2.60 (t, $J=6.8 \mathrm{~Hz}, 2 \mathrm{H}, \mathrm{CH}_{2} \mathrm{CH}_{2} \mathrm{CH}_{2} \mathrm{~S}$ ), 2.29 (s, 3H, OAc), 2.24 (s, 3H, OAc), 2.15 (s, 3H, OAc), 2.13 (s, 3H, OAc), 2.05 (s, 6H, OAc), 1.98 (s, 3H, OAc), $1.90-1.87\left(\mathrm{~m}, 2 \mathrm{H}, \mathrm{CH}_{2} \mathrm{CH}_{2} \mathrm{CH}_{2}\right) \mathrm{ppm} ;{ }^{13} \mathrm{C}$ NMR $(100 \mathrm{MHz}$, $\left.\mathrm{CDCl}_{3}\right): \delta 170.8,170.7,170.5,170.4,170.2,170.1,169.7,165.5,165.4$, $165.2,133.7,133.5,133.2,129.8(4), 129.6(2), 129.1,129.0,128.9$, 128.6(2), 128.5(2), 128.3(2), 98.8, 97.4, 82.2, 74.7, 70.8(2), 70.6, 70.3, 70.1, 69.6, 69.4, 69.2, 69.1, 66.6, 66.5, 66.1, 62.6, 62.3, 38.8, 31.8, 28.7(2), 28.1, 21.0, 20.8, 20.7, 20.6, 20.5(2), 20.4 ppm; MALDI-TOF MS $m / z$ calcd for $\mathrm{C}_{58} \mathrm{H}_{69} \mathrm{NO}_{25} \mathrm{~S}_{2} \mathrm{Na}[\mathrm{M}+\mathrm{Na}]^{+} 1266.3$, found 1266.4 .

\subsection{Tri- $\{[2,4-$ di-O-acetyl-3-O-(2,3,4-tri-O-benzoyl-6-O-acetyl- $\alpha$ - D-mannopyranosyl)-6-S-(2,3,4,6- tetra-O-acetyl- $\alpha$-D- mannopyranosyl)- $\alpha$-D-mannopyranosyloxypropylthio]ethyl $\}$ benzene 1,3,5-tricarboxamide (26)}

To a solution of compound $\mathbf{2 5}$ (102 $\mathrm{mg}, 0.08 \mathrm{mmol})$ and the acid chloride $4(7.1 \mathrm{mg}, 0.03 \mathrm{mmol})$ in $\mathrm{CH}_{2} \mathrm{Cl}_{2}(2 \mathrm{~mL})$ was added $\mathrm{NEt}_{3}$ $(11 \mu \mathrm{g}, 0.08 \mathrm{mmol})$ slowly at $0{ }^{\circ} \mathrm{C}$. The mixture was stirred at $0{ }^{\circ} \mathrm{C}$ for $30 \mathrm{~min}$, then the reaction mixture was concentrated under reduced pressure to give a residue that was subjected to silica gel column chromatography (EtOAc/Petroleum ether $=3 / 1)$ to afford $\mathbf{2 6}(70 \mathrm{mg}$, $67 \%)$ as a colorless syrup. $[\alpha]_{\mathrm{D}}^{25}+9.0\left(\mathrm{c} 2.1, \mathrm{CHCl}_{3}\right) ;{ }^{1} \mathrm{H} \mathrm{NMR}$ (400 MHz, $\left.\mathrm{CDCl}_{3}\right): \delta 8.36(\mathrm{~s}, 3 \mathrm{H}), 8.07(\mathrm{~d}, J=7.2 \mathrm{~Hz}, 6 \mathrm{H}), 7.96(\mathrm{~d}$, $J=7.6 \mathrm{~Hz}, 6 \mathrm{H}), 7.83(\mathrm{~d}, J=7.2 \mathrm{~Hz}, 6 \mathrm{H}), 7.60(\mathrm{t}, J=7.6 \mathrm{~Hz}, 3 \mathrm{H}), 7.53-7.44$ (m, 9H), 7.42-7.36 (m, 9H), $7.26(\mathrm{t}, J=7.6 \mathrm{~Hz}, 6 \mathrm{H}), 7.15(\mathrm{br}, 3 \mathrm{H}, \mathrm{NH})$, $5.92\left(\mathrm{t}, J=10.0 \mathrm{~Hz}, 3 \mathrm{H}, \mathrm{H}-4^{\prime}\right), 5.71\left(\mathrm{dd}, J=10.0,3.2 \mathrm{~Hz}, 3 \mathrm{H}, \mathrm{H}-3^{\prime}\right), 5.44$ $\left(\mathrm{d}, J=2.8 \mathrm{~Hz}, 3 \mathrm{H}, \mathrm{H}-2^{\prime}\right), 5.37\left(\mathrm{~d}, J=2.8 \mathrm{~Hz}, 3 \mathrm{H}, \mathrm{H}-2^{\prime \prime}\right), 5.35-5.25(\mathrm{~m}$, $18 \mathrm{H}, \mathrm{H}-1^{\prime}, \mathrm{H}-2, \mathrm{H}-4, \mathrm{H}-1^{\prime \prime}, \mathrm{H}-3^{\prime \prime}, \mathrm{H}-4^{\prime \prime}$ ), 4.83 (s, 3H, H-1), 4.41-4.38 ( $\left.\mathrm{m}, 6 \mathrm{H}, \mathrm{H}-5^{\prime}, \mathrm{H}-5^{\prime \prime}\right), 4.35-4.29$ (m, 6H, H-6a' , H-6a" ), 4.27-4.22 (m, $\left.6 \mathrm{H}, \mathrm{H}-6 \mathrm{~b}^{\prime \prime}, \mathrm{H}-3\right) 4.10$ (dd, $\left.J=12.4,1.6 \mathrm{~Hz}, 3 \mathrm{H}, \mathrm{H}-6 \mathrm{~b}^{\prime}\right), 3.91-3.86$ (m,
$6 \mathrm{H}, \mathrm{H}-5, \mathrm{OCH}_{2} \mathrm{CH}_{2}$ ), 3.62 (dd, $J=13.2,7.2 \mathrm{~Hz}, 6 \mathrm{H}, \mathrm{CH}_{2} \mathrm{NH}$ ), 3.54 (dt, $J=10.0,6.0 \mathrm{~Hz}, 6 \mathrm{H}, \mathrm{OCH}_{2} \mathrm{CH}_{2}$ ), 2.83 (dd, $J=14.0,2.8 \mathrm{~Hz}, 3 \mathrm{H}, \mathrm{H}-6 \mathrm{a}$ ), $2.78(\mathrm{~d}, J=8.0 \mathrm{~Hz}, 3 \mathrm{H}, \mathrm{H}-6 \mathrm{~b}), 2.74\left(\mathrm{t}, J=6.8 \mathrm{~Hz}, 6 \mathrm{H}, \mathrm{SCH}_{2} \mathrm{CH}_{2} \mathrm{NH}\right), 2.64$ (t, J=6.8 Hz, 6H, $\mathrm{CH}_{2} \mathrm{CH}_{2} \mathrm{CH}_{2} \mathrm{~S}$ ), 2.30 (s, 9H, OAc), 2.23 (s, 9H, OAc), 2.15 (s, 9H, OAc), 2.13 (s, 9H, OAc), 2.07 (s, 9H, OAc), 2.05 (s, 9H, $\mathrm{OAc}), 1.97$ (s, 9H, OAc), $1.94-1.86\left(\mathrm{~m}, 6 \mathrm{H}, \mathrm{CH}_{2} \mathrm{CH}_{2} \mathrm{CH}_{2}\right) \mathrm{ppm} ;{ }^{13} \mathrm{C}$ NMR (100 MHz, $\left.\mathrm{CDCl}_{3}\right): \delta$ 170.7(3), 170.6(3), 170.4(3), 170.1(3), 170.0(3), 169.7(6), 165.6(3), 165.5(3), 165.4(3), 165.2(3), 135.0(3), 133.7(3), 133.5(3), 133.2(3), 129.9(6), 129.8(6), 129.7(6), 129.2(3), 129.1(3), 128.9(3), 128.6(6), 128.5(6), 128.4(3), 128.3(6), 98.8(3), 97.4(3), 82.4(3), 74.8(3), 70.9(3), 70.8(3), 70.7(3), 70.4(3), 70.0(3), 69.5(3), 69.4(3), 69.2(3), 69.1(3), 66.6(3), 66.5(3), 66.2(3), 62.6(3), 62.3(3), 39.4(3), 32.0(3), 31.3(3), 28.9(3), 28.2(3), 21.1(3), 20.9(3), 20.8(3), 20.7(6), 20.6(6) ppm; MALDI-TOF MS $\mathrm{m} / \mathrm{z}$ calcd for $\mathrm{C}_{183} \mathrm{H}_{207} \mathrm{~N}_{3} \mathrm{O}_{78} \mathrm{~S}_{6} \mathrm{Na}[\mathrm{M}+\mathrm{Na}]^{+} 3910.5$, found $m / z$ 3910.5.

\subsection{Tri-\{[3-O-( $\alpha$-D-mannopyranosyl)-6-S-( $\alpha$-D-mannopyranosyl)- $\alpha$-D-mannopyranosyloxypropylthio] ethyl\}benzene 1,3,5- tricarboxamide (2)}

To a solution of $\mathbf{2 6}$ ( $56 \mathrm{mg}, 0.014 \mathrm{mmol}$ ) in anhydrous methanol ( $3 \mathrm{~mL}$ ) was added $1 \mathrm{M}$ solution of sodium methoxide in $\mathrm{MeOH}$ until $\mathrm{pH}$ 9-10 was reached. The reaction mixture is stirred at $\mathrm{rt}$ for $10 \mathrm{~h}$. Upon completion (TLC), more $\mathrm{MeOH}(5 \mathrm{~mL}$ ) was added, and the solution was neutralized with amberlite IR-120 $\left(\mathrm{H}^{+}\right)$. The filtrate was concentrated in vacuo in a rotary evaporator, and the residue was purified with Sephadex G-25. The desired fractions were lyophilized to give $\mathbf{2}$ (29 $\mathrm{mg}$, quantitative) as white foam. [ $\alpha]_{\mathrm{D}}^{25}+118$ $\left(c 0.75, \mathrm{H}_{2} \mathrm{O}\right) ;{ }^{1} \mathrm{H}$ NMR $\left(400 \mathrm{MHz}, \mathrm{D}_{2} \mathrm{O}\right): \delta 8.27(\mathrm{~s}, 3 \mathrm{H}, \mathrm{Ph}), 5.28(\mathrm{~s}, 3 \mathrm{H}$, $\left.\mathrm{H}-1^{\prime \prime}\right), 5.08\left(\mathrm{~s}, 3 \mathrm{H}, \mathrm{H}-1^{\prime}\right), 4.77(\mathrm{~s}, 3 \mathrm{H}, \mathrm{H}-1), 4.06-4.02(\mathrm{~m}, 9 \mathrm{H}, \mathrm{H}-2, \mathrm{H}-$ $2^{\prime}, \mathrm{H}-2^{\prime \prime}$ ), 3.97-3.60 (m, 48H), 3.57 (dd, $J=9.6,4.8 \mathrm{~Hz}, 3 \mathrm{H}, \mathrm{OCH}_{2} \mathrm{CH}_{2}$ ), $3.12(\mathrm{dd}, J=13.2,4.0 \mathrm{~Hz}, 3 \mathrm{H}, \mathrm{H}-6 \mathrm{a}), 2.85(\mathrm{t}, J=6.0 \mathrm{~Hz}, 6 \mathrm{H}$, $\mathrm{SCH}_{2} \mathrm{CH}_{2} \mathrm{NH}$ ), 2.78-2.71 (m, 9H, H-6b, $\mathrm{CH}_{2} \mathrm{CH}_{2} \mathrm{CH}_{2} \mathrm{~S}$ ), 1.99-1.89 (m, $\left.6 \mathrm{H}, \mathrm{CH}_{2} \mathrm{CH}_{2} \mathrm{CH}_{2}\right) \mathrm{ppm} ;{ }^{13} \mathrm{C} \mathrm{NMR}\left(100 \mathrm{MHz}, \mathrm{D}_{2} \mathrm{O}\right): \delta$ 168.5(3), 134.9(3), 129.0(3), 102.2(3), 99.7(3), 84.6(3), 77.9(3), 73.2(3), 73.2(3), 71.7(3), 71.4(3), 71.1(3), 70.3(3), 70.0(3), 69.6(3), 68.7(3), 67.0(3), 66.7(3), 66.1(3), 61.0(3), 60.8(3), 39.3(3), 31.7(3), 30.6(3), 28.4(3), 28.0(3) ppm; MALDI-TOF MS $\mathrm{m} / \mathrm{z}$ calcd for $\mathrm{C}_{78} \mathrm{H}_{129} \mathrm{~N}_{3} \mathrm{O}_{48} \mathrm{~S}_{6} \mathrm{Na}[\mathrm{M}+\mathrm{Na}]^{+}$2090.6, found 2090.6.

\subsection{Hemagglutination inhibition assays ${ }^{36}$}

Con A (5 mg) was dissolved in $10 \mathrm{~mL}$ of HEPES buffer with $100 \mathrm{mM} \mathrm{CaCl}_{2}, \mathrm{pH} 8.5$, and dialyzed into tris buffered saline (TBS), then phosphate buffered saline (PBS) for the assay. Protein solution concentration was estimated from its UV absorbance at $280 \mathrm{~nm}$. Rabbit red blood cells were stored as a $10 \%$ suspension in Alsever's solution and washed with PBS 3 times before the assay. The cells were re-suspended in PBS with 0.5\% BSA. The minimum concentration of inhibitor required to inhibit 8 units Con $A$ was determined as follows: Serial two fold dilutions of Con A in assay buffer were incubated with $50 \mu \mathrm{L}$ of the blood solution and examined for agglutination after $2 \mathrm{~h}$ at $23{ }^{\circ} \mathrm{C}$. The minimum concentration causing complete agglutination was defined as 1 unit. Then 8 unit Con A was incubated with serial two fold dilutions of the inhibitors for $3 \mathrm{~h}$ at $23^{\circ} \mathrm{C}$. Then $50 \mu \mathrm{L}$ of the blood solution was added and the samples were mixed and incubated for $2 \mathrm{~h}$ at $23^{\circ} \mathrm{C}$. The inhibiting dosage was determined as the minimum concentration of inhibitor at, which no agglutination is observed.

\subsection{Computational details}

To gain a deep insight into the complex structures of Con A and trimannoside, we carried out docking studies on them with SurflexDock algorithm ${ }^{40,41}$ of Sybyl-X software. ${ }^{42}$ The structure of Con A 
was downloaded from Protein Data Bank (PDB entry code 1ONA, A chain; PDB extracted from the Brookhaven Protein Database http:// www.rcsb.org/pdb) and used in initial docking studies. The structure of trisaccharide Man(3,6)Man-OMe is extracted from crystal structure 1ONA, while the structures of Man(3,6)Man-OAll and 1 were built by modifying Man(3,6)Man-OMe with Sybyl software. All the trimannosides were minimized with Powell method with default parameters provided by Sybyl. All hydrogen atoms were added, and Gasteiger-Huckel charges were calculated for ligand and protein. To generate an idealized protocol that represents the binding site, threshold was set to $0.5 \AA$ and bloat was set to $5 \AA$. During the docking, most of the parameters were the default values, except for post-docking minimization. The bindings of trimannosides and Con A were estimated using a variety of scoring functions within the consensus score (CScore). Pictures were drawn with PyMol software (http://www.pymol.org/).

\section{Acknowledgements}

This work was supported in partial by Strategic Priority Research Program of CAS (Grant No. XDB14040201), the MOST of China (Projects 2012ZX09502001, 2012CB822101), and NNSF of China (Projects 21372254, 21321004). We thank Dr. Min Li for mass spectra performance and Dr. Feifei Cheng for the suggestions in HA bioassay.

\section{Supplementary data}

Supplementary data related to this article can be found at http:// dx.doi.org/10.1016/j.carres.2015.05.001.

\section{References}

1. Varki A Glycobiology 1993:3:97-130.

2. Dwek RA. Chem Rev 1996;96:683-720.

3. Bertozzi CR, Kiessling LL. Science 2001;291:2357-64.

4. Zhao Y-Y, Takahashi M, Gu J-G, Miyoshi E, Matsumoto A, Kitazume S, et al. Cancer Sci 2008;99:1304-10.

5. Nishiyama K, Takakusagi Y, Kusayanagi T, Matsumoto Y, Habu S, Kuramochi K, et al. Bioorg Med Chem 2009;17:195-202.
6. Roth J. Chem Rev 2002;102:285-304.

7. Bartenschlager R, Sparacio S. Virus Res 2007;127:195-207.

8. Rozwarski DA, Swami BM, Brewer CF, Sacchettini JC. J Biol Chem 1998;273: 32818-25.

9. Dam TK, Roy R, Das SK, Oscarson S, Brewer CF. J Biol Chem 2000;275:14223-30.

10. Mammen M, Choi S-K, Whitesides GM. Angew Chem Int Ed 1998;37:2754-94.

11. Lee YC. FASEB J 1992;6:3193-200.

12. Dam TK, Brewer CF. Biochemistry 2008;47:8470-6.

13. Lehrer RI, Jung G, Ruchala P, Andre S, Gabius HJ, Lu W. I Immunol 2009;183: 480-90.

14. Bernardi A, Jimenez-Barbero J, Casnati A, De Castro C, Darbre T, Fieschi F, et al. Chem Soc Rev 2013;42:4709-27.

15. Kitov PI, Sadowska JM, Mulvey G, Armstrong GD, Ling H, Pannu NS, et al. Nature 2000;403:669-72.

16. Dam TK, Roy R, Pagé D, Brewer CF. Biochemistry 2001;41:1351-8.

17. Lepenies B, Lee J, Sonkaria S. Adv Drug Deliv Rev 2013:65:1271-81.

18. Chen O, Yang F, Du Y. Carbohydr Res 2005;340:2476-82.

19. Witczak ZJ, Chhabra R, Chen H, Xie X-Q. Carbohydr Res 1997;301:167-75.

20. Pachamuthu K, Schmidt RR. Chem Rev 2006;106:160-87.

21. Martín-Pastor M, Espinosa JF, Asensio JL, Jiménez-Barbero J. Carbohydr Res 1997;298:15-49.

22. Montero E, García-Herrero A, Asensio JL, Hirai K, Ogawa S, Santoyo-González F, et al. Eur J Org Chem 2000;2000:1945-52.

23. Aguilera B, Jiménez-Barbero J, Fernández-Mayoralas A. Carbohydr Res 1998;308:19-27.

24. Mikkelsen LM, Hernáiz MJ, Martín-Pastor M, Skrydstrup T, Jiménez-Barbero J. I Am Chem Soc 2002:124:14940-51.

25. Teumelsan N, Huang X. J Org Chem 2007;72:8976-9.

26. Elhalabi J, Rice KG. Carbohydr Res 2002;337:1935-40.

27. Wallace OB, Springer DM. Tetrahedron Lett 1998;39:2693-4.

28. Crich D, Li H. J Org Chem 2000;65:801-5.

29. Repetto E, Manzano VE, Uhrig ML, Varela O. J Org Chem 2011;77:253-65.

30. Liu Y, Liu J, Qi X, Du Y. J Org Chem 2012;77:7108-13.

31. Yang F, Hua Y, Du Y Carbohydr Res 2003:338:1313-8.

32. Blattner R, Furneaux RH, Ludewig M. Carbohydr Res 2006;341:299-321.

33. Dondoni A, Marra A. Chem Soc Rev 2012;41:573-86.

34. West KR, Bake KD, Otto S. Org Lett 2005:7:2615-8.

35. Osawa TMI. Methods Enzymol 1972;28:323-7.

36. Wolfenden ML, Cloninger MJ. J Am Chem Soc 2005;127:12168-9.

37. Rocha BAM, Delatorre P, Oliveira TM, Benevides RG, Pires AF, Sousa AAS, et al. Biochimie 2011;93:806-16.

38. Loris R, Maes D, Poortmans F, Wyns L, Bouckaert J. J Biol Chem 1996;271: 30614-8.

39. Duff Jr MR, Fyvie WS, Markad SD, Frankel AE, Kumar CV, Gascon JA, et al. Org Biomol Chem 2011;9:154-64.

40. Jain AN. J Med Chem 2003;46:499-511.

41. Jain AN. J Comput Aided Mol Des 2007;21:281-306.

42. Sybyl, Version 8.1. St. Louis, MO, USA: Tripos Inc.; 2008. 